\title{
Functional photosystem I maintains proper energy balance during nitrogen depletion in Chlamydomonas reinhardtii, promoting triacylglycerol accumulation
}

\author{
Mahmoud Gargouri ${ }^{1,2^{*}}$, Philip D. Bates ${ }^{1,3}$, Jeong-Jin Park ${ }^{1}$, Helmut Kirchhoff ${ }^{1}$ and David R. Gang ${ }^{\text {* }^{*}}$
}

\begin{abstract}
Background: Nutrient deprivation causes significant stress to the unicellular microalga, Chlamydomonas reinhardtii, which responds by significantly altering its metabolic program. Following $\mathrm{N}$ deprivation, the accumulation of starch and triacylglycerols (TAGs) is significantly altered following massive reprogramming of cellular metabolism. One protein that was found to change dramatically and early to this stress was TAB2, a photosystem I (PSI) translation initiation factor, whose transcript and protein levels increased significantly after only $30 \mathrm{~min}$ of $\mathrm{N}$ deprivation. A detailed physiological and omics-based analysis of an insertional mutant of Chlamydomonas with reduced TAB2 function was conducted to determine what role the functional PSI plays in regulating the cellular response to $\mathrm{N}$ deprivation.

Results: The tab2 mutant displayed increased acetate assimilation and elevated starch levels during the first $6 \mathrm{~h}$ of $\mathrm{N}$ deprivation, followed by a shift toward altered amino acid synthesis, reduced TAG content and altered fatty acid profiles. These results suggested a central role for PSI in controlling cellular metabolism and its implication in regulation of lipid/starch partitioning. Time course analyses of the tab2 mutant versus wild type under $\mathrm{N}$-deprived versus $\mathrm{N}$ replete conditions revealed changes in the ATP/NADPH ratio and suggested that TAG biosynthesis may be associated with maintaining the redox state of the cell during $N$ deprivation. The loss of ability to accumulate TAG in the tab2 mutant co-occurred with an up-regulation of photo-protective mechanisms, suggesting that the synthesis of TAG in the wild type occurs not only as a temporal energy sink, but also as a protective electron sink.

Conclusions: By exploiting the tab2 mutation in the cells of $C$. reinhardtii cultured under autotrophic, mixotrophic, and heterotrophic conditions during nitrogen replete growth and for the first 8 days of nitrogen deprivation, we showed that TAG accumulation and lipid/starch partitioning are dynamically regulated by alterations in PSI function, which concomitantly alters the immediate ATP/NADPH demand. This occurs even without removal of nitrogen from the medium, but sufficient external carbon must nevertheless be available. Efforts to increase lipid accumulation in algae such as Chlamydomonas need to consider carefully how the energy balance of the cell is involved in or affected by such efforts and that numerous layers of metabolic and genetic regulatory control are likely to interfere with such efforts to control oil biosynthesis. Such knowledge will enable synthetic biology approaches to alter the response to the $\mathrm{N}$ depletion stress, leading to rewiring of the regulatory networks so that lipid accumulation could be turned on in the absence of $\mathrm{N}$ deprivation, allowing for the development of algal production strains with highly enhanced lipid accumulation profiles.
\end{abstract}

\footnotetext{
*Correspondence: mahmoud.gargouri@gmail.com; gangd@wsu.edu ${ }^{1}$ Institute of Biological Chemistry, Washington State University, Pullman, WA 99164, USA

2 Present Address: Laboratory of Plant Molecular Physiology, Center of Biotechnology of Borj Cedria, P.O. Box 901, 2050 Hammam-Lif, Tunisia Full list of author information is available at the end of the article
} 
Keywords: Photosystem I, TAB2, Chlamydomonas reinhardtii, Nitrogen depletion, Triacylglycerol, Omics analysis

\section{Background}

Microalgae-derived biodiesel is a promising next generation biofuel due to its sustainability and biodegradability. Under certain conditions, such as nitrogen deprivation, strains of microalga such as Chlamydomonas reinhardtii are capable of producing significantly elevated levels of high-value compounds, such as triacylglycerols (TAGs) [1], which can be converted into multiple valuable fuels such as biodiesel, gasoline, and jet fuel [2]. Plant oils are the most energy dense form of biological energy storage [3]. Increasing the conversion of photosynthates into oils presents a potentially cost-efficient way to capture and store solar energy [4]. However, increasing oil production in microalgae and plants involves overcoming significant challenges [5]. The massive TAG accumulation that can occur in microalgae during nitrogen deprivation is correlated with a reduced abundance of many transcripts and proteins involved in photosynthesis, carbon fixation, and chlorophyll synthesis [6-8]. This leads ultimately to cessation of cell division and stalled growth. Therefore, an enhanced understanding of the relationship between maintaining active photosynthesis and high lipid accumulation will be required in order to rationally engineer the regulatory networks that control photosynthetic output in microalgae.

A number of other studies have focused on understanding the relationship between starch and lipid metabolism through examination of various Chlamydomonas wildtype strains and starchless mutants [9-11]. While it is clear that carbon accumulation switches from starch to lipid during $\mathrm{N}$ depletion, the role of energy production by PSI and PSII during the sensation of growth and TAG accumulation is still unclear. The light reactions of photosynthesis that produce energy and reducing equivalents (ATP and NADPH) for fatty acid synthesis may be a limiting factor with regards to TAG synthesis capability [12, 13]. Therefore, a better understanding of the mechanisms that regulate photosynthesis under nutrient starved (e.g., $\mathrm{N}$ deprivation) conditions is urgently needed.

Accumulation of carbon as TAG during $\mathrm{N}$ depletion demands much more reductant than accumulation of carbon as starch during $\mathrm{N}$ replete conditions. However, many previous studies suggest that changes in electron flow through PSI and PSII during $\mathrm{N}$ depletion do not favor production of NADPH for fatty acid synthesis. Several studies have used fluorescence measurements to begin unraveling the molecular mechanisms of photosynthesis inhibition in microalgae and diatoms, leading to the conclusion that photosystem II (PSII) is more highly affected than photosystem I (PSI) in response to nitrogen limitation [14, 15]. Systems biology approaches have been employed to understand the changes within the photosynthetic apparatus during $\mathrm{N}$ deprivation and have revealed an overall down-regulation of the majority of transcripts related to PSII and PSI after 2 days of $\mathrm{N}$ depletion [7, 16]. A quantitative proteomic study of starved-wild-type cells [17] demonstrated that down-regulation of PSII was coupled to up-regulation of PSI, suggesting that there is a relatively large capacity for cyclic electron (CEF) flow under $\mathrm{N}$ deprivation. Recently [8] demonstrated that linear electron flow (LEF) fell $\sim 15 \%$ more than CEF over the first $24 \mathrm{~h}$ of $\mathrm{N}$ deprivation. The increase of CEF capacity implies that there is an increase in demand for photosynthetically generated ATP relative to NADPH. However, lipid biosynthesis has a high NADPH demand [18]. The decreased PSII content and the linear electron transport under nitrogen deprivation raise the question of how lipid accumulation is initiated and maintained although photosynthetic NADPH production is reduced. It has been suggested that several mechanisms of alternative electron acceptor pathways, such as chlororespiration, are involved in regulating the ATP/NADPH ratio and photosynthetic output during the first $24 \mathrm{~h}$ of $\mathrm{N}$ deprivation [8]. Thus, a better understanding of ATP/NADPH production during $\mathrm{N}$ deprivation is needed. Clearly, specific regulatory proteins and perhaps signaling pathways are involved to maintain proper ATP and NADPH production for fatty acid synthesis under these conditions.

To identify these specific regulators, we previously analyzed the expression profiles of 417 putative regulatory genes in Chlamydomonas, including those involved in the regulation of transcription and translation, beginning from the onset of nutrient removal from the media through initiation of lipid accumulation. Several such regulatory proteins were found to respond to the nutrient stress. Among these, one stood out as an early and strong responder, the TAB2 gene [19]. TAB2 has been reported to be an RNA-binding protein that plays a key role in the initial steps of psaB translation and PSI assembly under normal nutrient conditions [20]. The F14 mutant strain of $C$. reinhardtii CC-1044 harbors a 14 nucleotide insertion near the $3^{\prime}$ end of the TAB2 gene, eliminating a highly conserved tryptophan at position 348 , which is required for the TAB2 protein to function properly in initiating psaB translation [20]. The tab2 mutant displays reduced psaB translation and a concomitant reduction in PSI assembly. 
Therefore, to unveil the relationship between photosynthesis and TAG accumulation in algae, we carried out a detailed characterization of the tab2 mutant and evaluated changes in the metabolome and proteome, as well as in photosynthetic parameters, relative to the CC-1044 wild type within growth time courses in $\mathrm{N}$ replete versus $\mathrm{N}$-depleted growth conditions.

\section{Methods}

\section{Strain, culture conditions, and sampling}

Two Chlamydomonas strains were used in this investigation. The wild-type strain, CC-125 wild-type $\mathrm{mt}+[137 \mathrm{c}]$, was obtained from the Chlamydomonas Genetics Center at Duke University (http://chlamycollection.org/) and the $t a b 2$ mutant strain (F14 $\mathrm{mt}+$ ) was kindly provided by the Institut de Biologie Physico-Chimique (IBPC), France. Both strains were grown at $25{ }^{\circ} \mathrm{C}$ in continuous light $\left(70 \mu \mathrm{mol}\right.$ photons $\left.\mathrm{m}^{-2} \mathrm{~s}^{-1}\right)$ in the presence of acetate in liquid cultures under shaking (150 rpm). Standard tris-acetate-phosphate (TAP) medium, which included $7.5 \mathrm{mM} \mathrm{NH}_{4} \mathrm{Cl}$, and high salt (HS) medium were previously described [21, 22]. For photoautotrophic growth, mutant cells were able to grow only on liquid culture when humidified ambient air was circulated through the culture flasks to increase $\mathrm{CO} 2$ availability. For nitrogen starvation studies, exponential phase $\left(4 \times 10^{6}\right.$ cells ml $\left.^{-1}\right)$ cultures were centrifuged at $1000 \times g$ for $5 \mathrm{~min}$ at room temperature, cell pellets kept and washed twice in TAP or HS medium either with or without nitrogen (TAP-N) and (HS-N). Pellets were then resuspended in medium without nitrogen and cells were grown under constant light with shaking. Samples for analysis were taken immediately after resuspension (time 0 ) or periodically during the growth time courses, and were pelleted as outlined above. Culture growth was monitored by counting cells with a hemocytometer [21]. Cell size was assessed using a Leica TCS SP5 laser-scanning confocal microscope with the assumption that cells are spherical for diameter calculations. Cells were immobilized with the addition of $10 \mu \mathrm{l}$ of $3 \mathrm{M}$ potassium iodide in $1 \mathrm{ml}$ algal culture medium and kept for $10 \mathrm{~min}$ before microscopy analysis.

\section{Quantitative RT-PCR conditions and analysis}

Total RNA was isolated from the cell pellet using the Trizol reagent (Ambion). One microgram of total RNA was used as a template for each RT-reaction following the manufacturer's instructions (qScript cDNA SuperMix, Quanta Bioscinces). Gene-specific primers were designed to amplify fragments of approximately 100$150 \mathrm{bp}$ in length. For the quantification of gene expression, qPCR was carried out on a Mastercycle Realplex 2 (Eppendorf) using the Perfecta Syber Green Fast Mix (Quanta Bioscinces, Gaithersburg, MD, USA). The actin gene served as internal control for the quantification assays in $C$. reinhardtii. For gene expression analysis by qPCR, the expression values were calculated according to the 2- $\Delta \Delta \mathrm{CT}$ method (for each gene, $\Delta \mathrm{CT}=\mathrm{CT}$, Gene - CT, housekeeping specific). The $\Delta \Delta \mathrm{Ct}$ calculation was validated using the plot of the log cDNA dilution versus $\Delta \mathrm{Ct}$. See supplemental material (Additional file 1: Table S1) for all primer sequences used in this work.

\section{Proteomic analysis}

Chlamydomonas strains were harvested by centrifugation at $3000 \times g$ for $5 \mathrm{~min}$ at $4{ }^{\circ} \mathrm{C}$. Proteins were extracted from 50-100 mg of cells as described previously [23] and were quantified using the Qubit Protein Assay Kit (Invitrogen, Carlsbad, USA) in accordance with the supplier's protocol for the Qubit 2.0 fluorometer (Invitrogen). $100 \mu \mathrm{g}$ of each sample was digested with trypsin and analyzed on an Orbitrap Fusion Tribrid mass spectrometer (Thermo Scientific, Rockford, USA) coupled with an EASY-nLC (Thermo Scientific). Data were processed and searched using SIEVE 2.1 (Thermo Scientific), and all searches were performed against the Chlamydomonas protein database from Phytozome v. 9.0 (http://www. phytozome.net) and NCBI chloroplast (http://www.ncbi. nlm.nih.gov/nuccore/BK000554) and mitochondrion (http://www.ncbi.nlm.nih.gov/nuccore/NC_001638.1) databases.

\section{Metabolomic analysis}

The relative levels of amino and organic acids and sugars were determined by gas chromatography-mass spectrometry (GC-MS). The lyophilized cells $(5 \mathrm{ml}$ of culture pelleted as above) were transferred to a 1.5$\mathrm{ml}$ eppendorf tube and disrupted using a steel ball (5 mm). To each sample, $0.75 \mathrm{ml}$ of extraction buffer (methanol:chloroform:water, 5:2:2 v/v) was added. Samples were then vortexed for $10 \mathrm{~min}$ at room temperature, followed by centrifugation at $16,000 \times g$ for $2 \mathrm{~min}$. The supernatant was collected, evaporated to dryness and spiked with $2 \mu \mathrm{l}$ of internal standard mixture solution of methyl esters and C30 linear chain length fatty acids. After $5 \mu \mathrm{l}$ pyridine methoxyamine hydrochloride was added, each sample was incubated for $90 \mathrm{~min}$ in a thermostatic bath kept at $30^{\circ} \mathrm{C}$. Samples were then derivatized by the addition of $45 \mu \mathrm{l} N$-methyl- $N$-trimethylsilyltrifluoroacetamide (MSTFA $+1 \%$ TMCS, Pierce, Rockford, IL, USA) for $30 \mathrm{~min}$ at $37^{\circ} \mathrm{C}$. Derivatized primary metabolites were analyzed by gas chromatographytime of flight mass spectrometry (GC-TOFMS) on a Pegasus 4D GC-MS system (LECO, St. Joseph, MI, USA) equipped with an $\mathrm{RTX}^{\circledR}-5$ Sil MS with Integra-Guard ${ }^{\circledR}$ column $(30 \mathrm{~m} \times 0.25 \mathrm{~mm}$ ID $\times 0.25 \mu \mathrm{m}$ film thickness $)$ from Restek (GmbH, Bad Homburg, Germany) and an 
MPS-2 autosampler (Gerstel, Muehlheim, Germany). All injections were performed in splitless mode $(1 \mu \mathrm{l})$ with helium as carrier gas at a constant flow of $1 \mathrm{ml} \mathrm{min}{ }^{-1}$. The column was held isothermally at $50{ }^{\circ} \mathrm{C}$ for $1 \mathrm{~min}$ and ramped at $20^{\circ} \mathrm{C} \mathrm{min}^{-1}$ to $330{ }^{\circ} \mathrm{C}$. ChromaTOF software version 4.41 equipped with the LECO/Fiehn Metabolomics database was used for primary metabolite data processing.

\section{Lipid analysis \\ Total lipid analysis}

A simplified and modified protocol using direct transmethylation [24] was applied to microalgal cultures for high-speed screening purposes. Briefly, 5 million cells were harvested by centrifugation at $10,000 \times g$ for $2 \mathrm{~min}$. The cells were freeze-dried and extracted with $1 \mathrm{ml}$ of $2.5 \%(\mathrm{v} / \mathrm{v})$ conc. sulfuric acid in methanol, with $10 \mu \mathrm{g}$ of C15:0 TAG used as a triacylglycerol internal standard. The transesterification reaction was allowed to occur at $80{ }^{\circ} \mathrm{C}$ for $60 \mathrm{~min}$. After cooling to room temperature, $0.2 \mathrm{ml}$ of hexane and $1.5 \mathrm{ml}$ of water were added and vortexed. The organic phase was separated from the water phase by centrifugation at $4000 \times g$ for $2 \mathrm{~min}$. The resulting fatty acid methyl esters (FAMEs), present in the organic phase, were analyzed by gas chromatography coupled to a flame ionization detector (FID) using an EC Wax column (30 m, $0.53 \mathrm{~mm}$ i.d., $1.20 \mu \mathrm{m}$ film thickness; Alltech). The GC conditions were as follows: split mode injection (1:40), injector and flame ionization detector temperature: $260{ }^{\circ} \mathrm{C}$; oven temperature program: $190{ }^{\circ} \mathrm{C}$ for $2 \mathrm{~min}$, then increasing at $10{ }^{\circ} \mathrm{C} \mathrm{min}-1$ to $250{ }^{\circ} \mathrm{C}$ and holding this temperature for $5 \mathrm{~min}$.

\section{Neutral lipid analysis}

Neutral lipids were extracted using a procedure modified from [25]. Cells were collected by centrifugation at $10,000 \times g$ for $10 \mathrm{~min}$ and were resuspended in $0.7 \mathrm{ml}$ of $1 \mathrm{mM}$ EDTA in $0.15 \mathrm{M}$ acetic acid. This solution was vortexed for $10 \mathrm{~min}$ after the addition of $3 \mathrm{ml}$ methanol:chloroform $(2: 1, \mathrm{v} / \mathrm{v})$. Then, $1.5 \mathrm{ml}$ of chloroform and $1.2 \mathrm{ml}$ of $\mathrm{KCl} 0.88 \%(\mathrm{w} / \mathrm{v})$ were added. After vortexing, the phases were separated by centrifugation at $2000 \times g$ for $2 \mathrm{~min}$. The lower, chloroform phase was removed to a clean tube using a glass transfer pipette. The upper, aqueous phase was re-extracted with an additional $2 \mathrm{ml}$ of chloroform. This solution was vortexed and centrifuged as before. The lower organic layer was then combined with that obtained in the first extraction and the total lipid extract was taken to dryness under a gentle stream of nitrogen. Lipids were redissolved in $200 \mu \mathrm{l}$ of chloroform for further analysis. Triacylglycerols (TAGs) were separated from other lipids using thin layer chromatography (TLC). Typically, around $0.5 \mathrm{mg}$ of lipid extract was loaded as a spot onto a $20 \times 20 \mathrm{~cm}$ Partisil K6 silica gel $60 \AA$ TLC plate (Whatman, Maidstone, UK). Plates were then developed using hexane/diethyether/acetic acid $(80 / 20 / 2, \mathrm{v} / \mathrm{v} / \mathrm{v})$ for $30 \mathrm{~min}$. The TAG fraction was determined based on migration of standards, and was visualized under UV light after the plate was sprayed with a fine mist of $0.01 \%$ primuline in acetone: $\mathrm{H}_{2} \mathrm{O}(4: 1)$. The silica corresponding to the TAG fraction was carefully scrapped off of the TLC plate and was transmethylated for GC-FID analysis as described above. However, the recovery of TAG from the silica, transmethylation, and quantification of the FAMEs by GC-FID is a time consuming method. A solid-phase extraction method using Discovery DSC-Si SPE cartridges (Supelco, Bellefonte, PA, USA) was developed for high throughput analysis of the neutral lipid fraction. Cartridges containing $100 \mathrm{mg}$ of solid phase were conditioned with $6 \mathrm{ml}$ of methanol and then $6 \mathrm{ml}$ of chloroform. The samples (200 $\mu \mathrm{l}$ in chloroform) were loaded onto the cartridges using a syringe. The neutral lipid fraction was eluted with $1 \mathrm{ml}$ chloroform:methanol (99:1). This fraction contained the TAGs and DAGs while the polar lipid fraction was retained on the cartridge. The latter was eluted with $1 \mathrm{ml}$ chloroform:methanol (2:1). The neutral fraction was taken to dryness under a gentle stream of nitrogen and the FAMEs were generated and quantified by GC-FID as described above. Results obtained by the solid-phase extraction method were not significantly different from those obtained by recovery of the TAG fraction from the TLC plate.

\section{Starch, chlorophyll quantification, and cell viability}

Total starch was quantified using an enzymatic starch assay kit including a commercial amyloglucosidase solution (Sigma SA-20) to convert starch to glucose (SigmaAldrich, St. Louis, MO, USA). A total of 4 million cells were harvested by centrifugation for $2 \mathrm{~min}$ at room temp. The pellet was resuspended in $1 \mathrm{ml} 80 \%$ acetone and mixed vigorously to extract chlorophyll. After centrifugation at high speed for $1 \mathrm{~min}$, the supernatant was used to determine the total chlorophyll content based on the absorbance values at 663 and $645 \mathrm{~nm}$ following Arnon's method [26]. The resulting pellet was taken to dryness in a fume hood and then resuspended in $400 \mu \mathrm{l}$ of water. Total starch content was measured using a standard method [27] after the starch had been solubilized by autoclaving the resuspended pellet for $15 \mathrm{~min}$ at $120{ }^{\circ} \mathrm{C}$. To assess cell viability, cells grown in TAP-N medium were harvested at different time points in the growth time courses $(0,12,24,48,96$, and $144 \mathrm{~h})$. For each time point, $0.1 \mathrm{ml}$ of the culture was diluted 1:100 and then $0.1 \mathrm{ml}$ of the diluted culture was spread on a TAP agar plate and allowed to grow for 1 week. Viability 
percentages corresponded to the total number of colonies counted for each time point relative to the 0 -h time point as described by [28].

\section{Oxygen evolution and photosynthesis parameters}

Steady-state rates of oxygen evolution in nitrogendeprived cells were determined using a water-jacketed $\left(20{ }^{\circ} \mathrm{C}\right)$ Clark-type oxygen electrode (Oxylab, Hansatech Instruments, King's Lynn, UK). Aliquots of cells $(1 \mathrm{ml})$ were withdrawn from the flasks and dark adapted for $20 \mathrm{~min}$ before being transferred to the measuring chamber. Cells were illuminated with 500,800 , and $1300 \mu \mathrm{mol} \mathrm{m}{ }^{-2} \mathrm{~s}^{-1}$ red actinic light for $5 \mathrm{~min}$ each in series.

Pulse amplitude modulated (PAM) chlorophyll fluorescence measurements were conducted using a DUALPAM-100 measuring device (Oxylab, Heinz Walz GmbH, Germany). $F_{0}$ was determined using $1.5 \mathrm{ml}$ aliquots of either $\mathrm{N}$-deprived or $\mathrm{N}$ replete cells collected from time course experiments and incubated in the measuring chamber in the dark for $15 \mathrm{~min}$ prior to analysis. $F_{\mathrm{m}}$ is the maximum chlorophyll fluorescence from dark-adapted cells and was determined by application of a $0.6 \mathrm{~s}$ saturating pulse of $1870 \mu \mathrm{mol}$ photons $\cdot \mathrm{m}^{-2} \mathrm{~s}^{-1} . F_{\mathrm{t}}$ was determined after the cells had been illuminated with an actinic light source of $95 \mu \mathrm{mol}$ photons $\cdot \mathrm{m}^{-2} \mathrm{~s}^{-1}$ for $230 \mathrm{~s}$, during which saturating pulses were applied every $20 \mathrm{~s}$ to analyze $F_{\mathrm{m}}^{\prime}$ values, where $F_{\mathrm{m}}^{\prime}$ is the maximum chlorophyll fluorescence under actinic light [29]. $F_{\mathrm{v}} / F_{\mathrm{m}}$ as an indicator of the maximum quantum efficiency of PSII was calculated using $F_{0}$ and $F_{\mathrm{m}}$ values according to the formula $\left(F_{\mathrm{m}}-F_{0}\right) / F_{\mathrm{m}}$. For calculating the efficiency of PSII photochemistry in illuminated cells $\left(\right.$ PPSII $\left.=\left(F_{\mathrm{m}}^{\prime}-F_{\mathrm{t}}\right) / F_{\mathrm{m}}^{\prime}\right)$, $F_{\mathrm{m}}^{\prime}$ and $F_{\mathrm{t}}$ values observed after $210 \mathrm{~s}$ of applying actinic light were used [30]. Data were analyzed using SigmaPlot 11 software.

\section{K fluorescence spectroscopy}

The algae cells at a chlorophyll concentration of $\sim 3 \mu \mathrm{g} 10^{-6}$ cells were shock frozen in liquid nitrogen and were excited with a broad light source $(450-800 \mathrm{~nm})$ produced with a halogen lamp and Schott BG18, Corning 9782, and LOT heat mirror filters. Triplicate emission spectra per sample were averaged and corrected using an internal dye standard. To compare relative fluorescence changes between PSII and PSI maximum absorbance at 685 and $715 \mathrm{~nm}$, respectively, the spectra were normalized to chlorophyll a concentration.

\section{Flash-spectrophotometric assays}

The levels of $\mathrm{P}_{700}$ for wild-type and mutant cells during nitrogen starvation were probed by observing absorbance changes at $700 \mathrm{~nm}$ using an instrument described previously [31, 32]. Saturating single-turnover actinic flashes were provided by a xenon flash lamp (approximately $2 \mathrm{~J}$ total energy output per pulse, $5 \mu$ s duration), filtered with two layers of a red filter (Schott RG665, Schott Glass Technologies, Duryea, PA, USA). Measurements were carried out on dark-adapted cells at room temperature for $10 \mathrm{~min}$. The total amount of photo-oxidizable $\mathrm{P}_{700}$ was determined by measuring the $700 \mathrm{~nm}$ absorbance change upon illumination in the presence of $100 \mu \mathrm{M}$ DCMU [(3,4-dichlorophenyl)-1,1-dimethylurea] as artificial inhibitor.

\section{Acetate quantification}

Acetate remaining in culture media was quantified using the Acetate Colorimetric Assay Kit (BioVision, Milpitas, CA, USA). Both $\mathrm{N}$ replete and $\mathrm{N}$-depleted TAP medium for wild-type and tab2 mutant cells contained $17.5 \mathrm{mM}$ acetate prior to culturing at $0 \mathrm{~h}$. One milliliter of the culture was withdrawn from the flask at each time point. The supernatant was filtered through a $0.45 \mu \mathrm{m}$ filter membrane after centrifugation at $14,000 \times g$ for $5 \mathrm{~min}$ and then was stored at $-20{ }^{\circ} \mathrm{C}$. All samples were analyzed using 96-well flat bottom plates (Costar, Corning, NY, USA) following the kit protocol by measuring the absorption maximum at $450 \mathrm{~nm}$ in a SPECTRAmax PLUS microplate spectrophotometer system (Sunnyvale, CA, USA).

\section{Determination of ATP:ADP and NADPH:NADP ratios}

ADP was measured using a colorimetric assay kit including a commercial enzyme solution to convert ADP to ATP and pyruvate. The generated pyruvate was quantified spectrophotometrically at $570 \mathrm{~nm}$ (BioVision, Milpitas, CA, USA). However, ATP was measured using a colorimetric method based on glycerol kinase activity that utilizes ATP for the phosphorylation of glycerol to generate glycerol phosphate, which is a measurable at $570 \mathrm{~nm}$ (BioVision, Milpitas, CA, USA). For both ATP and ADP assays, $1 \mathrm{ml}$ of Chlamydomonas culture was harvested by centrifugation at $14,000 \times g$ for $2 \mathrm{~min}$ at $4{ }^{\circ} \mathrm{C}$. The pellet was flash frozen in liquid $\mathrm{N}_{2}$ and disrupted by a TissueLyser II for $30 \mathrm{~s}$. Then, the cells were homogenized in $100 \mu \mathrm{l}$ of ADP or ATP assay buffer before to additional disruption by sonication in an ice water bath for $5 \mathrm{~min}$. The solution was centrifuged $15,000 \times g$ for 2 min at $4{ }^{\circ} \mathrm{C}$ to remove insoluble material. Four microliters of the supernatant were used to perform the ADP and ATP measurement according to the manufacturer's protocol (BioVision). The ADP and ATP concentrations were calculated using standard curves. The amounts of $\mathrm{NADP}^{+}$and NADPH were determined using a NADP/ NADPH Quantitation Kit according to the manufacturer's instructions (Sigma-Aldrich, St. Louis, MO, USA). The cells were sonicated in $200 \mu \mathrm{l}$ NADP/NADPH 
extraction buffer for $20 \mathrm{~min}$ in an ice water bath and then centrifuged $13,000 \times g$ for $10 \mathrm{~min}$ at $4{ }^{\circ} \mathrm{C}$. The supernatant was filtered using a $10 \mathrm{kDa}$ cutoff spin filter (BioVision) to remove proteins from the extract before use in the assay. All measurements were performed in triplicate in 96-well plates and quantified at $450 \mathrm{~nm}$ using the colorimetric assay according to the kit instructions.

\section{Results}

\section{Effects of nitrogen depletion on transcript and protein levels of TAB2 in WT and the tab2 mutant}

To investigate the function of TAB2 in Chlamydomonas during $\mathrm{N}$ deprivation, a comparison between the parental strain (CC-125) and the $t a b 2$ mutant was performed using growth time courses either in the presence ( $\mathrm{N}$ replete) or absence ( $\mathrm{N}$ depleted) of nitrogen added to the growth medium (TAP media was used except where indicated, as described in "Methods"). Transcriptome, proteome, and metabolome data were collected across replicate time courses (at least 3 replicate samples per time point were analyzed). We first tested whether the $t a b 2$ mutation affects the expression level of the TAB2 gene during $\mathrm{N}$ deprivation. As shown in Fig. 1a, quantitative real-time PCR demonstrated that the transcript level of TAB2 in the WT was up-regulated 2.5-fold within the first $30 \mathrm{~min}$ following $\mathrm{N}$ depletion, whereas in the tab2 mutant, the $T A B 2$ transcript levels were $50 \%$ of WT at time 0 and remained low throughout the time course. TAB2 primers for real-time PCR analysis we designed to be specific to $T A B 2$ gene and not also to $T A B 1$ which is another (PSI) translation initiation factor of PsaB. The proteomic results revealed that after $48 \mathrm{~h}$ of $\mathrm{N}$ deprivation TAB2 protein abundance was twofold higher in the WT relative to the time 0 control, whereas in the tab2 mutant, the TAB2 protein levels were initially significantly lower than in the WT and then decreased more than $61 \%$ by $48 \mathrm{~h}$ (Fig. 1b). To visualize more global patterns of protein level changes, volcano plots of the full set of identified proteins for both the WT and tab2 strains were generated, comparing results from $48 \mathrm{~h}$ to time 0 (Fig. 1c, d). For the significantly changing proteins in the WT, although more proteins were down-regulated than up-regulated, the fold-changes observed were relatively small (almost all were less than fourfold different in expression level, Fig. 1c). In contrast, for the tab2 mutant, most proteins that changed significantly in expression increased, and many of these changed by more than fourfold (Fig. 1d). Thus, although the TAB2 protein was originally described as a translation initiation factor for psaB, when it is mutated, significant global changes occur in the proteome. The experiments described below were designed to identify the mechanism responsible for these changes and to determine what affect they had on overall cellular physiology.
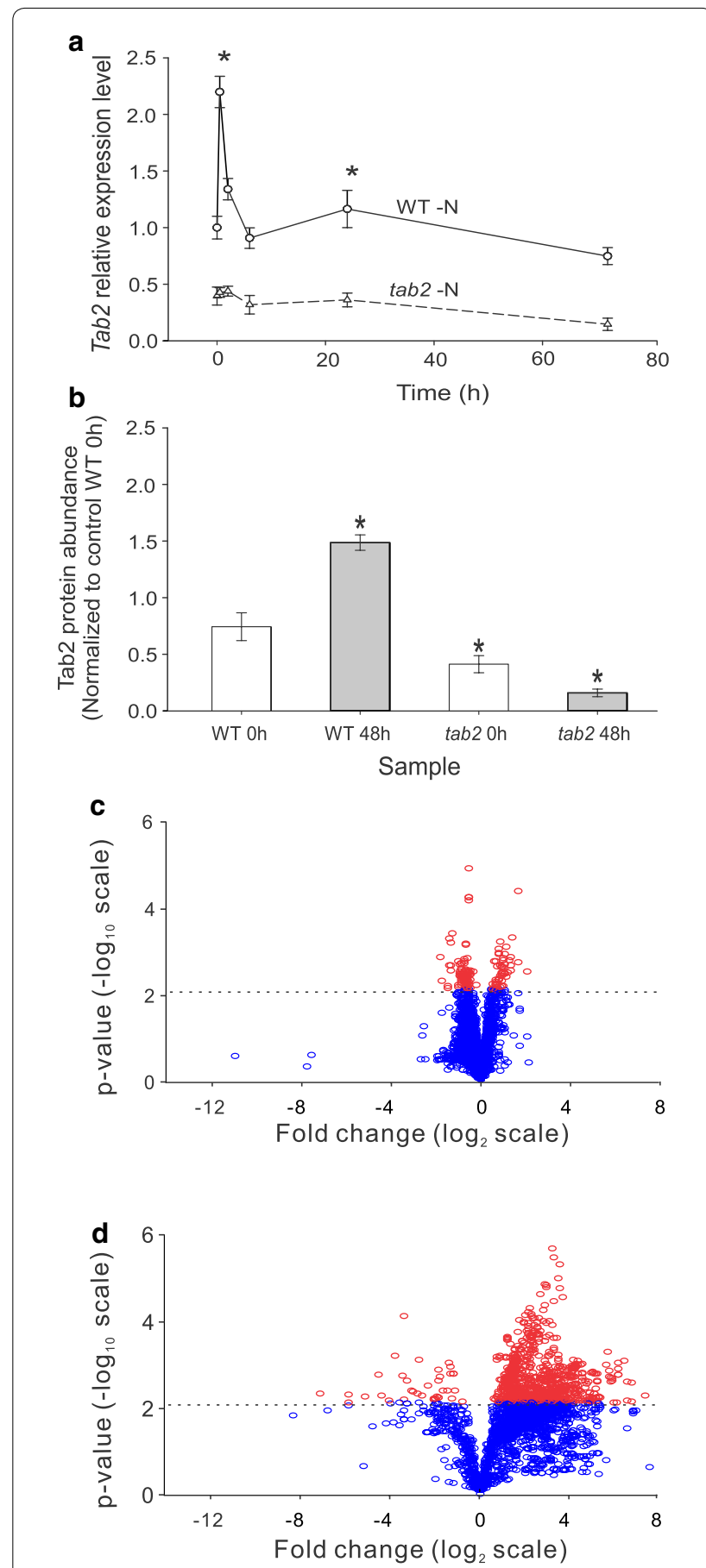

Fig. 1 Characterization of Tab2 levels in wild type (CC125) and the tab2 mutant during the $\mathrm{N}$ deprivation time course. a Relative expression level of the TAB2 gene, normalized to the expression of Actin (see Additional file 1:Table S1) and then the relative abundance of each time point was normalized to time 0 . b Abundance of the TAB2 protein, normalized to $\mathrm{WT}$ at time 0 . Data are presented as mean $\pm \mathrm{SE}$ $(\mathrm{n}=3)$. ${ }^{*} p<0.05$. c, d Volcano plots of overall proteomic changes in WT and the tab2 mutant, respectively, comparing fold change of proteins in nitrogen depleted $(48 \mathrm{~h}$ ) relative to nitrogen replete (time $0)$ conditions. Proteins with significant changes $(p<0.05)$ are shown by red ellipses. The stringent cutoff of $p<0.01$ is shown by a dotted line 
The tab2 mutant loses viability and has a reduced cell size following $\mathrm{N}$ deprivation

To investigate whether the reduced TAB2 protein level in the mutant cells altered cell physiology during $\mathrm{N}$ deprivation, the chlorophyll content, cell viability and cell size were measured across the time courses. Under $\mathrm{N}$ deprivation, chlorophyll levels dropped over time in both the WT and the tab2 mutant, but this reduction (see Fig. 2) was greater in the mutant (80\%) than in WT $(60 \%$ reduction). That corresponded with the observed greater down-regulation of most enzymes involved in chlorophyll and carotenoid biosynthesis in tab2 compared to WT (Additional file 2: Figure S1). The decrease in chlorophyll content mirrored a dramatic decline of viability in tab2 cells after 6 days of $\mathrm{N}$ deprivation (Fig. 2). Furthermore, the decrease of TAG accumulation in tab2 under $\mathrm{N}$ deprivation was correlated $\left(R^{2}=0.88\right)$ with a decrease in cell cross-sectional area (Additional file 3: Figure S2). However, there was no correlation between carbohydrate levels and cell size, indicating that the increased cell size in the WT corresponded to an increase of TAG content during $\mathrm{N}$ deprivation, as has been previously suggested [33].

\section{Effect on photosynthetic activity and respiration following $\mathrm{N}$ deprivation}

To assess whether the observed differences in physiological parameters between WT and tab2 were related to changes in the photosynthetic apparatus during $\mathrm{N}$ deprivation, we used PAM chlorophyll fluorescence to compare changes in the overall photosynthetic capacity in
WT and tab2 cells during the growth time courses. The maximum quantum efficiency of PSII $\left(F_{\mathrm{V}} / F_{\mathrm{m}}\right)$ remained constant (around 0.8) in dark-adapted cells growing in $\mathrm{N}$ replete conditions, while it steadily decreased in both strains under $\mathrm{N}$-depleted conditions, reaching 0.43 (Fig. 3a), indicative of a decrease in the amount of active photosystem II. No significant differences were observed between the tab2 and WT strains under these conditions. The efficiency of PSII in light-adapted cells ( $\Phi I I)$, on the other hand, decreased $10-20 \%$ in the mutant compared to the WT during both $\mathrm{N}$ replete and $\mathrm{N}$-depleted conditions (Fig. 3b). Non-photochemical quenching (NPQ) under both $\mathrm{N}$ replete and deprivation conditions was also measured (Fig. 3c), showing that NPQ increased markedly in $t a b 2$ following $\mathrm{N}$ deprivation and its level was 1.6-fold higher in tab2 than WT after 4 days. Under $\mathrm{N}$ replete conditions, NPQ levels were also higher in tab2 (4.7-fold) compared to WT by $48 \mathrm{~h}$, suggesting a reduction of LEF capacity in tab2 relative to WT under both conditions. The efficiency of electron transfer in PSII is partly dependent on the number of open/oxidized quinone A (QA) molecules available. The qL parameter can be used to determine the percent of open PSII reaction centers (oxidized QA pool) [34]. During N deprivation, qL fell more dramatically in tab2 than in WT, indicating a clear decrease in the abundance of open reaction centers in the mutant as compared to WT, while in $\mathrm{N}$ replete conditions, $\mathrm{qL}$ levels remained constant throughout the time course in both mutant and WT (Fig. 3d). However, $\mathrm{qL}$ levels were lower in tab2, indicating a decrease in the abundance of open reaction centers in the mutant. This

\begin{tabular}{|c|c|c|c|c|c|c|}
\hline Time $(\mathrm{h})$ & 0 & 12 & 24 & 48 & 96 & 144 \\
\hline \multicolumn{7}{|c|}{ Wild type } \\
\hline Cell area size $\left(\mu \mathrm{m}^{2}\right)$ & $20.4 \pm 2.1$ & $26.0 \pm 0.9$ & $26.0 \pm 1.3$ & $37.1 \pm 1.3$ & $39.9 \pm 3.3$ & $39.6 \pm 2.1$ \\
\hline Cell count $\left(10^{6} / \mathrm{ml}\right)$ & $4.2 \pm 0.3$ & $4.5 \pm 0.1$ & $5.1 \pm 0.3$ & $5.3 \pm 0.6$ & $5.1 \pm 0.2$ & $5.1 \pm 0.7$ \\
\hline $\begin{array}{l}\text { Total chlorophyll } \\
\left(\mu \mathrm{g} / 10^{6} \text { cells }\right)\end{array}$ & $3.2 \pm 0.1$ & $2.8 \pm 0.3$ & $2.8 \pm 0.1$ & $2.7 \pm 0.1$ & $1.5 \pm 0.2$ & $1.0 \pm 0.1$ \\
\hline Viability (\%) & $100 \pm 11$ & $98 \pm 5$ & $91 \pm 10$ & $89 \pm 7$ & $62 \pm 11$ & $60 \pm 4$ \\
\hline \multirow{2}{*}{\multicolumn{7}{|c|}{ Culture Appearance }} \\
\hline & & & & & & \\
\hline Cell area size $\left(\mu \mathrm{m}^{2}\right)$ & $16.4 \pm 1.1$ & $21.2 \pm 1.4$ & $23.8 \pm 0.7$ & $33.2 \pm 0.9$ & $24.8 \pm 2.2$ & $14.2 \pm 0.3$ \\
\hline Cell count $\left(10^{6} / \mathrm{ml}\right)$ & $4.1 \pm 0.5$ & $3.2 \pm 0.7$ & $3.5 \pm 0.2$ & $3.3 \pm 0.9$ & $3.1 \pm 0.1$ & $3.3 \pm 0.4$ \\
\hline $\begin{array}{l}\text { Total chlorophyll } \\
\left(\mu \mathrm{g} / 10^{6} \text { cells }\right)\end{array}$ & $2.7 \pm 0.1$ & $2.2 \pm 0.2$ & $1.7 \pm 0.1$ & $1.3 \pm .1$ & $0.63 \pm 0.2$ & $0.36 \pm 0.1$ \\
\hline Viability $(\%)$ & $100 \pm 9$ & $86 \pm 4$ & $80 \pm 5$ & $66 \pm 3$ & $34 \pm 7$ & $21 \pm 5$ \\
\hline Culture Appearance & & santses & 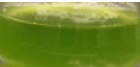 & 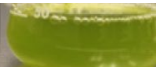 & 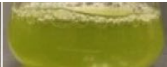 & (1) \\
\hline
\end{tabular}



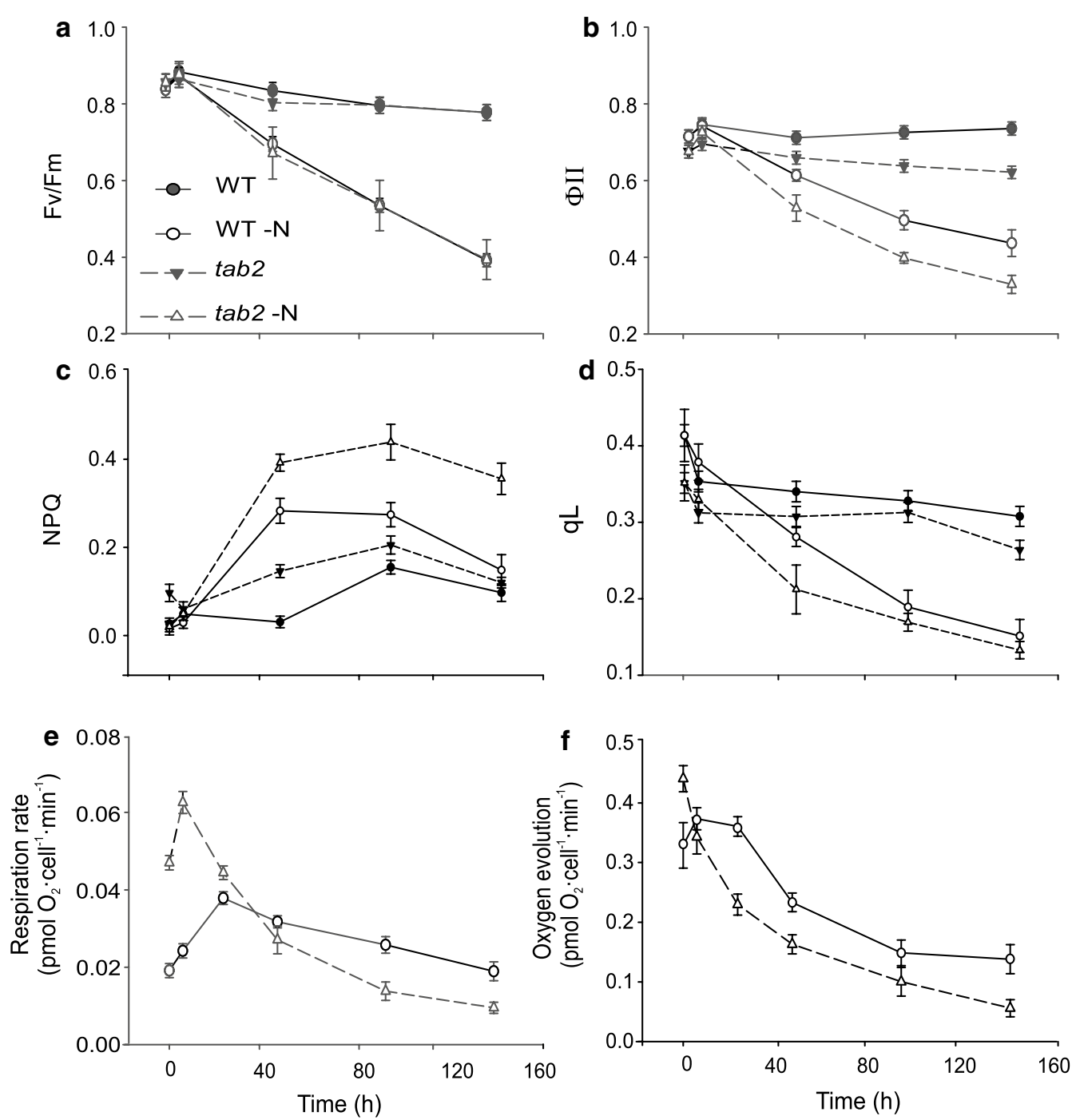

Fig. 3 Comparison of photosynthetic properties in WT and tab2 cells. a Maximum quantum yield of PSII (FV/Fm) determined in dark-adapted cells grown under N replete (WT solid circle, tab2 solid triangle) and N-depleted (WT open circle, tab2 open triangle) conditions. b Efficiency of PSIl photochemistry in illuminated cells $(\Phi \|)$ under the conditions described above (more details are in "Methods"). c Non-photochemical quenching and $\mathbf{d}$ relative amount of oxidized QA determined in cells grown under $\mathrm{N}$ replete and $\mathrm{N}$-depleted conditions. $\mathbf{e}$, $\mathbf{f}$ The rates of oxygen uptake (respiration rate) and evolution were determined in WT and tab2 cells under N-depleted conditions (see legend above of N-depleted condition). Three biological replicates were included in the experiments, with error bars representing SE of the mean

decrease in photosynthetic efficiency was accompanied by a significant down-regulation of the levels of PSII, PSI and cytochrome $b 6 f$ complex subunits in the mutant (Additional file 4: Figure S3) and demonstrated that the QA pool was increasingly reduced over time in the mutant as compared to the WT.

In addition, the levels of the mitochondrial electron transport chain proteins were observed to be very highly up-regulated in tab2 compared to the WT during N deprivation (Additional file 5: Figure S4). For this reason, we performed oxygen evolution analysis on both strains during $\mathrm{N}$ deprivation. The respiration rate in WT increased initially to 0.37 pmol $\mathrm{O}_{2}$ cell $^{-1} \mathrm{~min}^{-1}$, reaching a maximum at $\sim 24 \mathrm{~h}$ (Fig. 3e). The dark respiration rate of the tab2 mutant increased significantly within $6 \mathrm{~h}$ compared to WT ( threefold increase) during $\mathrm{N}$ deprivation, but then dropped to approximately half the level of WT during the last few days of the time course. In contrast, the oxygen evolution in illuminated samples in $t a b 2$ decreased to roughly half that of WT by $24 \mathrm{~h}$ and remained lower than the WT throughout the rest of the time course (Fig. 3f). Photosynthetic oxygen evolution did not drop in the WT until after $24 \mathrm{~h}$. This delay in establishing hypoxic conditions in the WT compared 
to the tab2 mutant is probably due to a prolonged PSII activity in the WT. Taken together, these findings demonstrated that net oxygen production dropped steeply and was accompanied with an increase of respiration rate during the first $24 \mathrm{~h}$ in the mutant compared to the WT, suggesting that probably a high degradation of chloroplast in the PSI defective mutant for buildup mitochondrial components, consistent with [7] study on adaptation of Chlamy cells to $\mathrm{N}$ deprivation.

To gain further insight into the effects of the $t a b 2$ mutation on the amount of intact PSII and PSI complexes during $\mathrm{N}$ deprivation, we used $77 \mathrm{~K}$ fluorescence analysis. The amplitude of the PSII-associated signal (around $685 \mathrm{~nm}$ ) in WT increased within the first $24 \mathrm{~h}$, after which it dropped through the rest of the time course. In contrast, the PSI-associated signal (around $715 \mathrm{~nm}$ ) in WT cells did not increase at first, but decreased after $24 \mathrm{~h}$ and then remained constant across the rest of the time course (Fig. 4a; Additional file 6: Figure S5). In tab2 cells, the response was very similar but less pronounced for PSII (Fig. 4b). For the PSI-associated signal, the time course for $t a b 2$ is similar to WT but the absolute amplitude is about $50 \%$ lower, indicating reduced abundance of PSI complexes as expected for a PSI translation initiation mutant (see also next paragraph). Consequently, the ratio of PSII to PSI was significantly higher in the tab2 mutant relative to the WT (Fig. 4c), supporting the proteomics and transcriptomics results described above.

To verify whether the $t a b 2$ mutation resulted in a general impairment of functional PSI during $\mathrm{N}$ deprivation, we measured the absolute amounts of photo-oxidizable $\mathrm{P}_{700}$ (Fig. 4d) in the presence of the PSII inhibitor, 3-(3,4-dichlorophenyl)-1,1-dimethylurea (DCMU, Diuron). The level of intact PSI centers in the mutant was initially about $60 \%$ of the WT. This is in line with $77 \mathrm{~K}$ fluorescence results (see above). During the $\mathrm{N}$ deprivation time course, the PSI content in the WT and tab2 peaked within the first $6 \mathrm{~h}$ and then decreased by about $15 \%$ in the WT and $50 \%$ in the mutant by $48 \mathrm{~h}$. By 4 days of $\mathrm{N}$ deprivation, the amount of PSI had decreased only slightly in the WT, while in the mutant, PSI had reached very low levels. These findings confirm the important role of the TAB2 protein in maintaining the levels of PSI and therefore retention of active photosynthetic apparatus during $\mathrm{N}$ deprivation. These results are also consistent with a previous suggestion [14] that the PSI reaction center proteins are more stable than PSII during $\mathrm{N}$ deprivation in microalgae, although that had been not reported for Chlamydomonas until now.

Although the chlorophyll content decreased by 12 and $22 \%$ in the WT and the mutant after $12 \mathrm{~h}$ of N deprivation, respectively, functional fluorescence measures, $F \mathrm{v} / F \mathrm{~m}$ and $\Phi_{\mathrm{ii}}$, decreased only slightly, suggesting

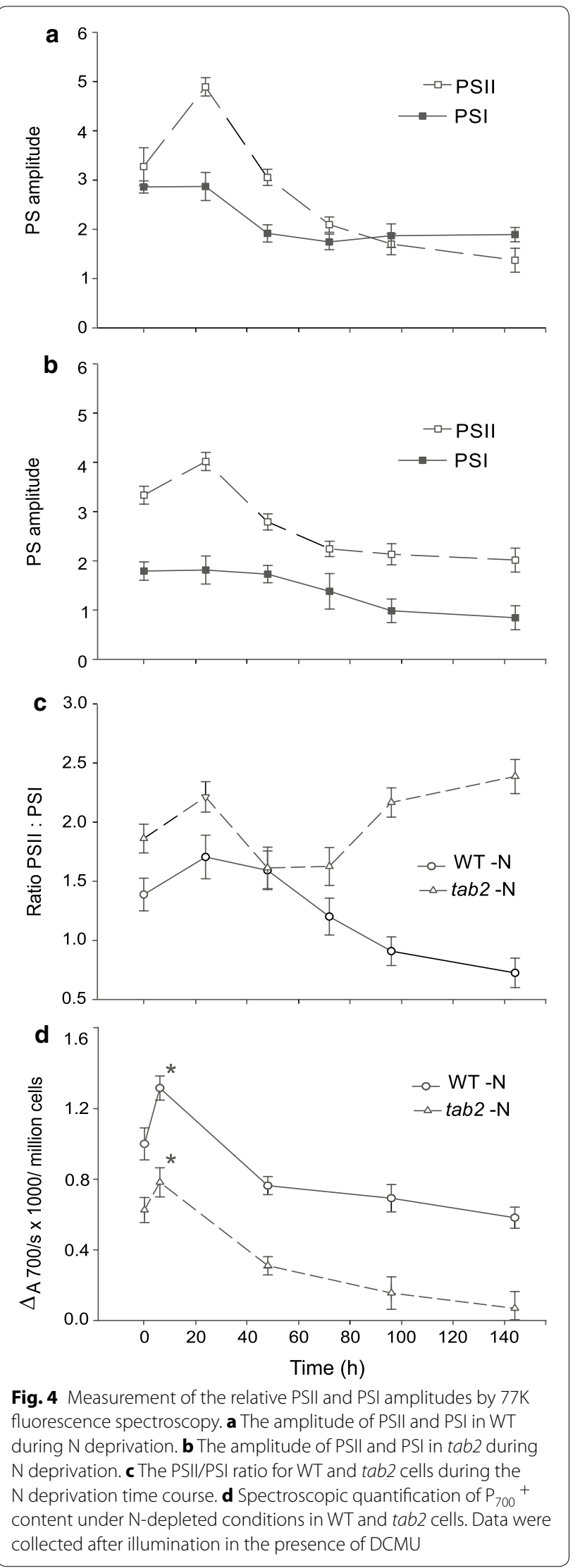


that those decreases in chlorophyll content had only a minimal impact on the efficiency of PSII. The observed decrease in PSI subunits and the measurable oxidizable $\mathrm{P}_{700}$ levels in the tab2 mutant (threefold decrease compared to the WT) led to the question of whether that decrease in PSI levels might have an impact on NADPH levels and therefore an impact on TAG synthesis in the mutant. We hypothesized that the TAB2 protein, by playing a crucial role in maintaining active PSI complex, may be indirectly responsible for enabling the production of TAG in the WT during $\mathrm{N}$ deprivation, at least within the first $24 \mathrm{~h}$ following $\mathrm{N}$ deprivation, and that in the $t a b 2$ mutant, reduced levels of PSI could have broad reaching impacts on metabolism.

\section{The tab2 mutation leads to drastic changes in ATP/NADPH ratios during $\mathrm{N}$ deprivation}

To further understand the function of TAB2 in modulating the relationship between photosynthesis and TAG accumulation that was observed in this investigation, we monitored the change in ATP, ADP, NADPH, and $\mathrm{NADP}^{+}$levels in cells across the growth time courses and compared these values to each other. In the very early phase of $\mathrm{N}$ deprivation, by $2 \mathrm{~h}$, the NADPH/NADP ${ }^{+}$ratio increased significantly in the WT, while it dropped in the tab2 cells. By $24 \mathrm{~h}$, the WT ratio dropped and then it remained consistently around 1 throughout the rest of the time course (Fig. 5a). On the other hand, the tab2 cells recovered quickly, with the ratio returning to normal (around 1) by $6 \mathrm{~h}$. By $48 \mathrm{~h}$, however, the tab2 ratio had dropped significantly and it remained low throughout the rest of the time course compared to the ratio in WT. In contrast, the ATP/ADP remained consistently low for the WT but slowly increased in the tab2 mutant over the initial few days of the time course (Fig. 5b). The increase in ATP in the WT during the last stages of $\mathrm{N}$ deprivation is likely the result of cyclic electron flow around PSI, which decreases the flow of electrons into the NADPH pool. That implies that there is an increase in demand for photosynthetically generated ATP relative to NADPH, most likely needed for maintenance and remodeling of the Chlamydomonas proteome during $\mathrm{N}$ deprivation [8].

The ATP/NADPH ratio thus declined from 1.5 to 0.6 in WT cells during the first $6 \mathrm{~h}$ of $\mathrm{N}$ deprivation (Fig. 5c). This ratio remained low during the first $24 \mathrm{~h}$, but returned to ca. 1.5 by $48 \mathrm{~h}$, where it remained for the duration of the time course. In contrast, the initial decline was absent in the tab2 mutant, and the ATP/NADPH ratio remained relatively constant for the duration of the time course, with a value of about 2-2.5. This difference in the ATP/NADPH ratio response for the tab2 mutant versus the wild type may be the result of a difference in demand for NADPH associated with FA biosynthesis in

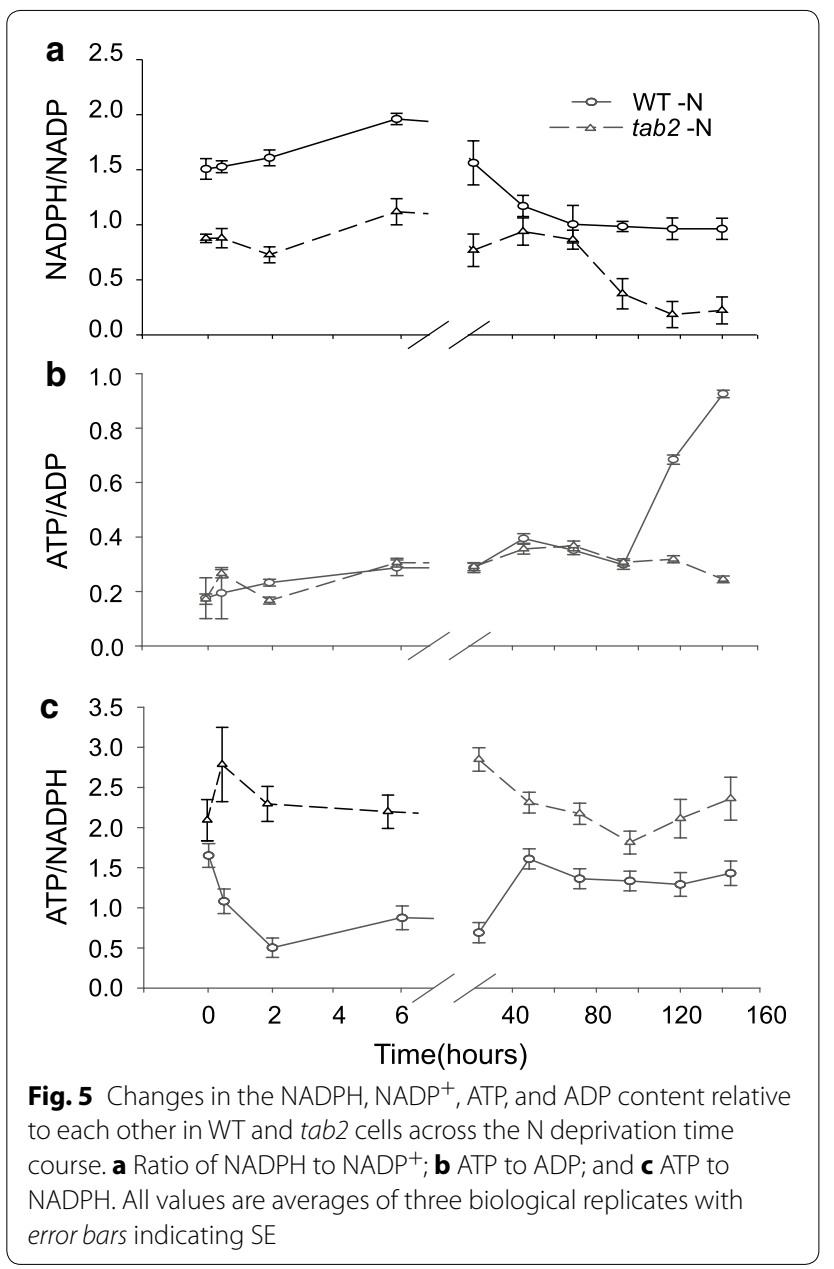

tab2. Therefore, experiments to test this hypothesis were performed, as outlined below.

\section{The tab2 mutation leads to an increase of TAG and starch levels under $\mathrm{N}$ replete conditions}

To determine what changes in metabolism resulted from the tab2 mutation, the levels of primary metabolites and neutral lipids and FA composition were compared across the time courses, focusing first on the $\mathrm{N}$ replete time course, where cells were grown in TAP media for 8 days until nutrients ran out. TAG amounts in the mutant were found to be greater than twofold higher than in the WT across the first $24 \mathrm{~h}$ of the $\mathrm{N}$ replete time course (see Fig. 6a). The tab2 mutant had a higher starting level of neutral lipid content but both the mutant and WT significantly increased neutral lipid levels per cell by the same magnitude within $48 \mathrm{~h}$. Neutral lipid levels in tab2 then decreased to levels just higher than WT and these levels remained relatively constant in both cell lines for the remainder of the time course, after 8 days (Additional file 7: Figure S6A). Thus, under the initial $\mathrm{N}$ replete 

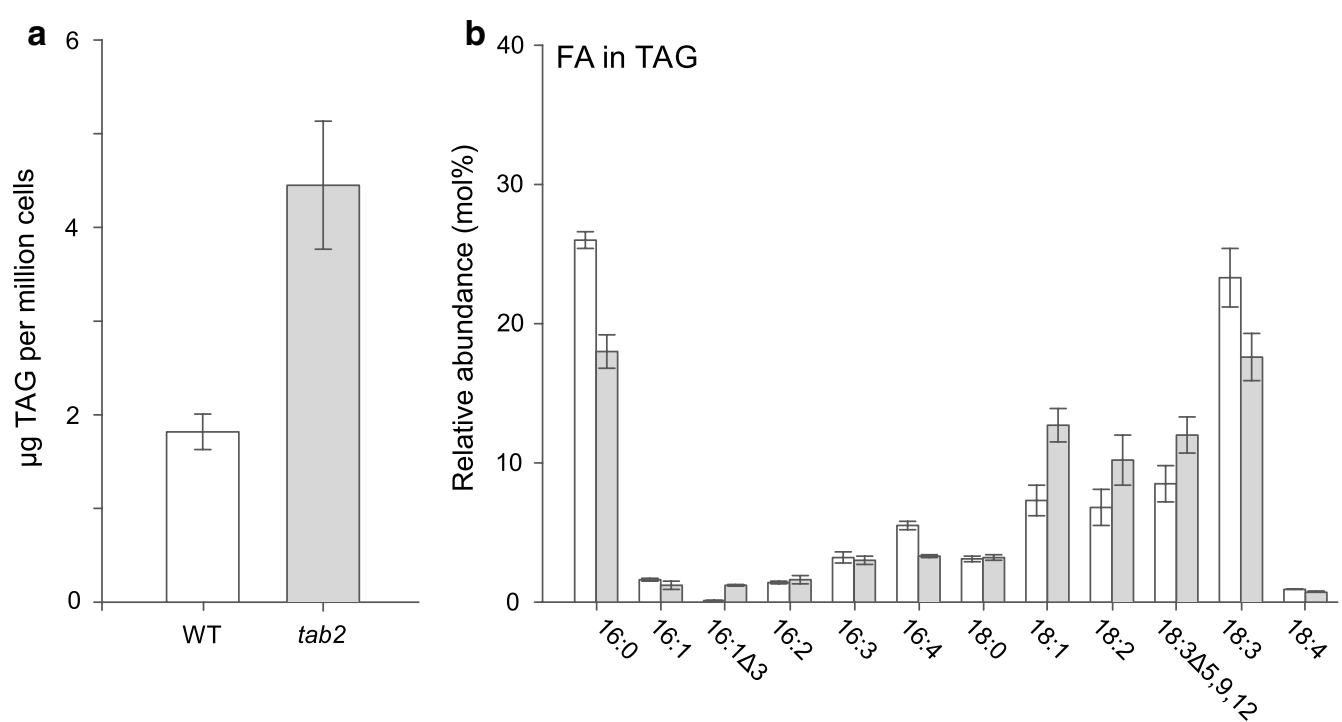

Fig. 6 Analysis of lipids in WT and tab2 mutant cells grown in N replete medium. a Comparison of TAG content in the WT versus tab2 cells. b Mol (\%) of specific fatty acids in TAG isolated from WT (white) and tab2 (gray) cells. Values are averages of triplicate biological samples. Error bars indicate SE of the mean

conditions, the higher overall metabolic capacity of the WT cells not defective in PSI led eventually to the same TAG accumulation end point as tab2 in the long time course when the media progressively ran out of $\mathrm{N}$ and then $\mathrm{C}$.

Compared to the WT, the tab2 mutant had higher levels of 18:1 (12.7 versus 7.3\%) and 18:2 (10.2 versus 6.8\%) fatty acids (Fig. 6b). In contrast, WT cells were rich (compared to the mutant) in polyunsaturated FA (PUFA) species containing 3 and 4 double bonds, characteristic of membrane lipids, such as $16: 4$ (5.5\% in WT versus $3.3 \%$ in tab2) and 18:3 (23.3 versus $17.6 \%$ ) (Fig. 6b). The knockdown of $t a b 2$ levels leads to an increase in specific enzymes required for elimination of reactive oxygen species. Oleate (18:1) is a major constituent of wild-type TAG, accounting for $25 \%$ of the acyl groups in TAG, but represents only up to $10 \%$ of acyl groups in diacylglyceryltrimethylhomoserine and phosphatidylethanolamine [28], major lipid classes in Chlamydomonas membranes. Thus, a high relative 18:1 level in the mutant growing under $\mathrm{N}$ replete condition is indicative of an emphasis by the cells on TAG production instead of cell membrane production at the end of the time course (Additional file 7: Figure S6B, C).

To better understand the partitioning of carbon reserves in $t a b 2$, and to see what role starch synthesis may play in that process, we monitored the starch levels in tab2 and WT cells during the $\mathrm{N}$ replete time course. Starch levels in the mutant rose rapidly during the first $24 \mathrm{~h}$ and reached levels 9 times higher than was observed for the WT by the end of the time course (Fig. 7a). This enhancement of starch and TAG production in the tab2 mutant under $\mathrm{N}+$ conditions, particularly in the presence of acetate, leads to the suggestion that altered photosynthetic efficiency (due to reduced PSI levels) is a condition required to promote energy storage compound accumulation without $\mathrm{N}$ depletion. This will be described in more detail below.

\section{The role of acetate assimilation in TAG and starch production in the tab2 mutant}

Under optimal growth conditions, WT cells do not accumulate high levels of energy storage compounds (Additional file 7: Figure S6; Fig. 7a). When algae encounter stresses, such as a lack of nitrogen, cell division slows down and carbon is remobilized to produce energy storage products, such as lipids and/or starch in response to altered nutrient availability. In our study, the TAG and starch content in the tab2 mutant increased significantly under mixotrophic conditions (where acetate was present as a carbon source) not lacking for $\mathrm{N}$ (Fig. 6a), something that did not occur in the WT cells. Thus, the external carbon source may play a significant role in production of energy storage products in the tab2 mutant. To verify this hypothesis, we monitored acetate utilization in tab2 and WT cells across the $\mathrm{N}$ replete and $\mathrm{N}$ deprivation time courses. The acetate uptake in $\mathrm{N}$ replete media by tab2 cells was $\sim 2.3$-fold higher than by WT cells after $24 \mathrm{~h}$ (Fig. 9), which is also in line with the higher respiration rate observed in the mutant compared to the WT (Fig. 3e). Coincidently, the time point at which lipids and starch began to increase in the mutant under these 


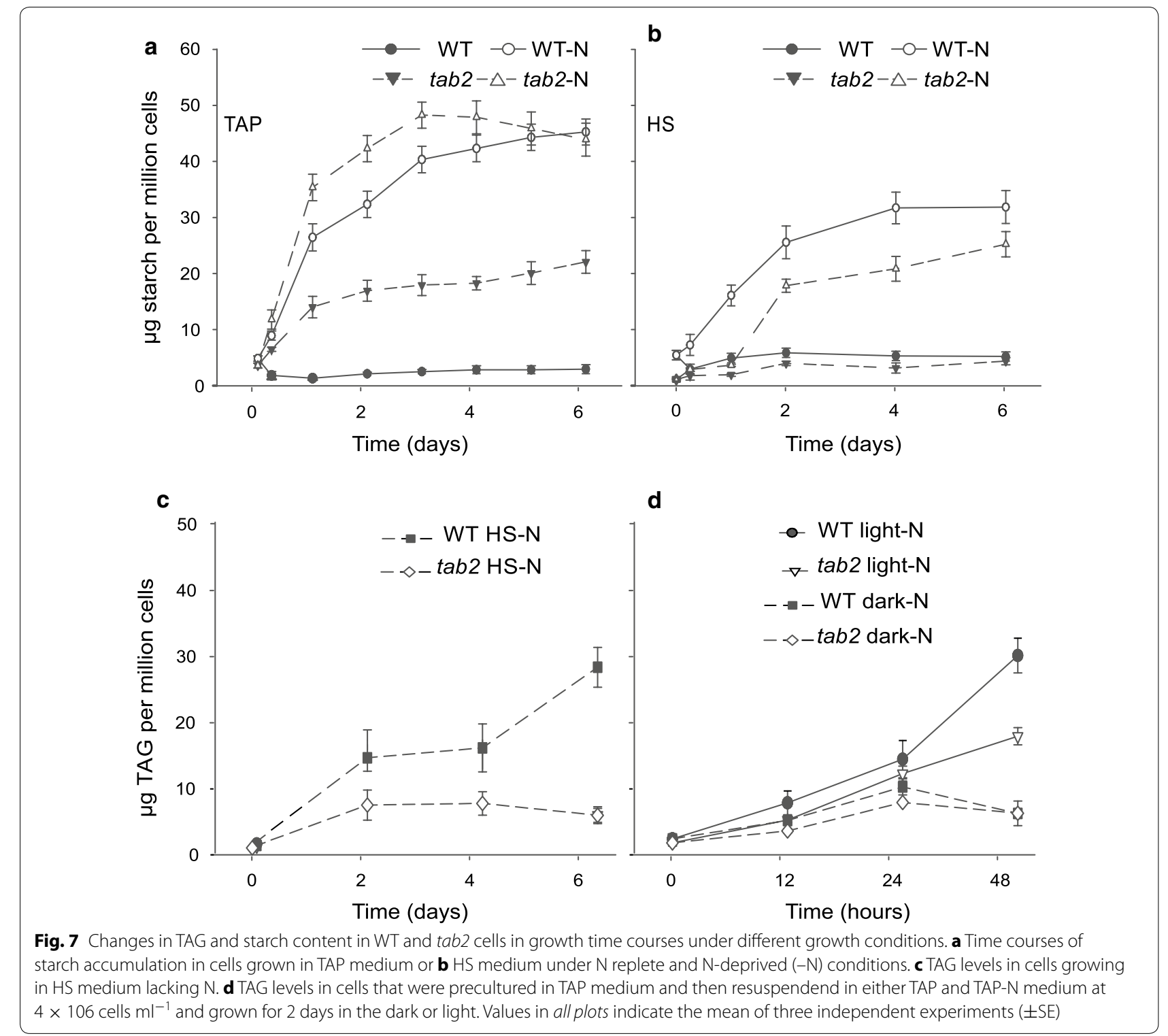

conditions was just when the levels of acetate in the media began to drop. To further confirm the high use of acetate caused by the tab2 mutation, algal cells were grown in HS medium (lacking acetate) or in the dark. The TAG content of the cells showed no increase under these conditions compared to those grown under the mixotrophic conditions (Fig. 7c, d). Moreover, the starch content remained lower than that observed in the WT (Fig. 7b). In addition, acetate uptake was higher in the mutant than in the WT within the first $24 \mathrm{~h}$ following $\mathrm{N}$ depletion, enabling the observed starch accumulation in the mutant (Fig. 7a). This higher rate of acetate assimilation in tab2 cells under $\mathrm{N}$ deprivation can be explained by the observed up-regulation of the two enzymes, ACK2 (A8IR49) and PAT2 (A8IZZ9), involved in acetate uptake via the acetate-phosphate pathway (Additional file 11: Figure S10A).

The above results demonstrated lower starch and lipid accumulation in the tab2 mutant for cells grown in photoautotrophic or heterotrophic culture conditions compared to mixotrophic conditions with either $\mathrm{N}$ present or absent, with a concomitant increase in acetate utilization (Figs. 7, 8, 9). Thus, the simultaneous presence of acetate and light appears to be a necessary condition for the small increase of TAG in the tab2 mutant, otherwise the mutant accumulates preferentially starch over lipids compared to the WT, due presumably to the lower energy requirement for the biosynthesis of the former over the latter [35]. These results are consistent with the idea that the addition of an external carbon source 


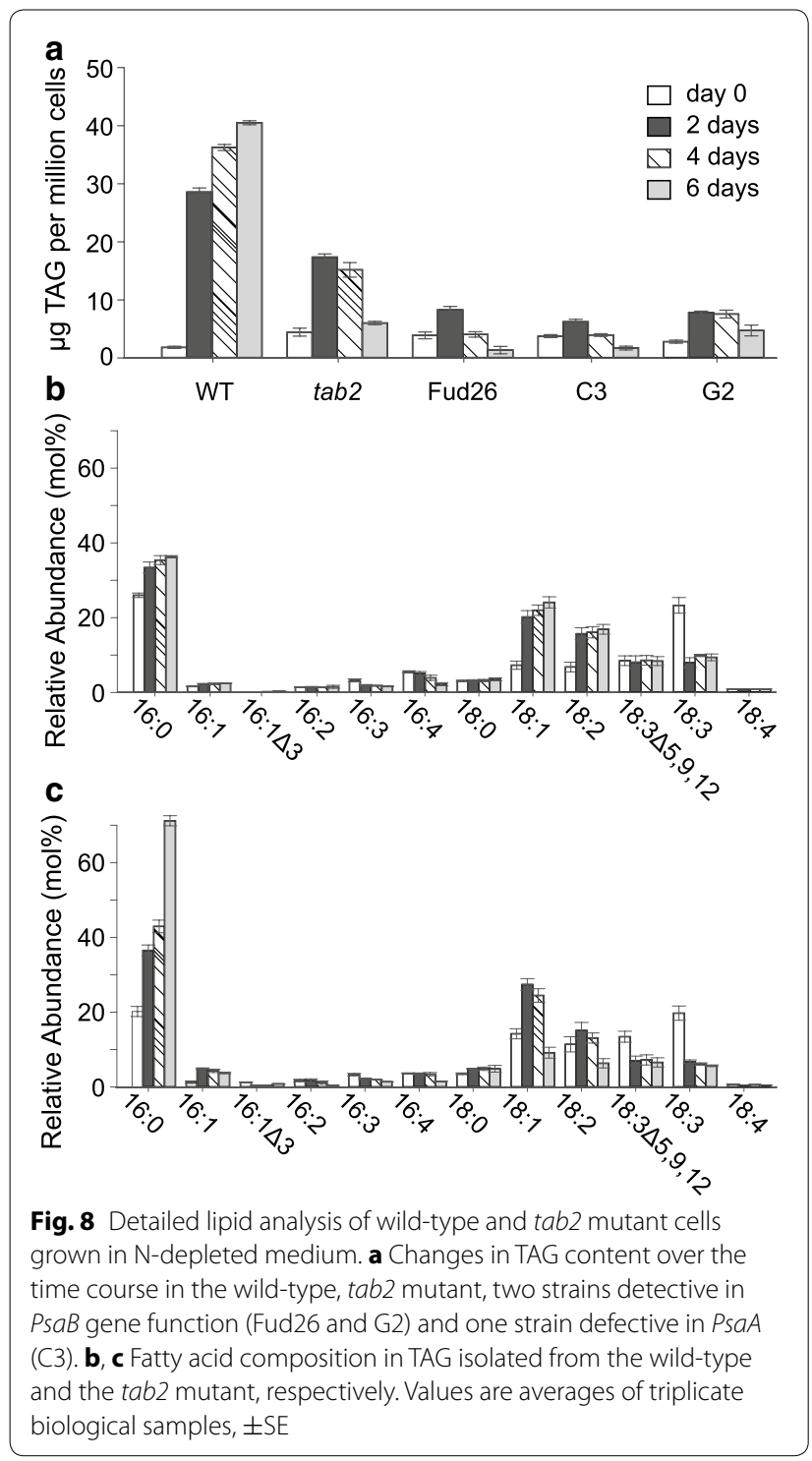

can quantitatively substitute for photosynthetic carbon assimilation to drive growth and storage compound accumulation in Chlamydomonas under some circumstances (i.e., defective PSI). Here, it is noteworthy to mention that the experiments reported above were possible to be performed since we have been able to grow in this present work the mutant in liquid culture with a delay of 4 days to raise the exponential phase when its cultured in TAP medium and a delay of 8-10 days when its cultured in HS medium as compared to the WT growth rate. However, we have observed the same growth rate as Dauvillee et al. [20] reported that mutant cells were unable to grow photoautotrophically, and tab2 grew poorly on acetate-containing medium under high light $(60 \mu \mathrm{E} /$ $\mathrm{m} 2 / \mathrm{s}$ ) in agar plates. The delay in growth of tab2 in HS medium could suggest the development of a suppressor

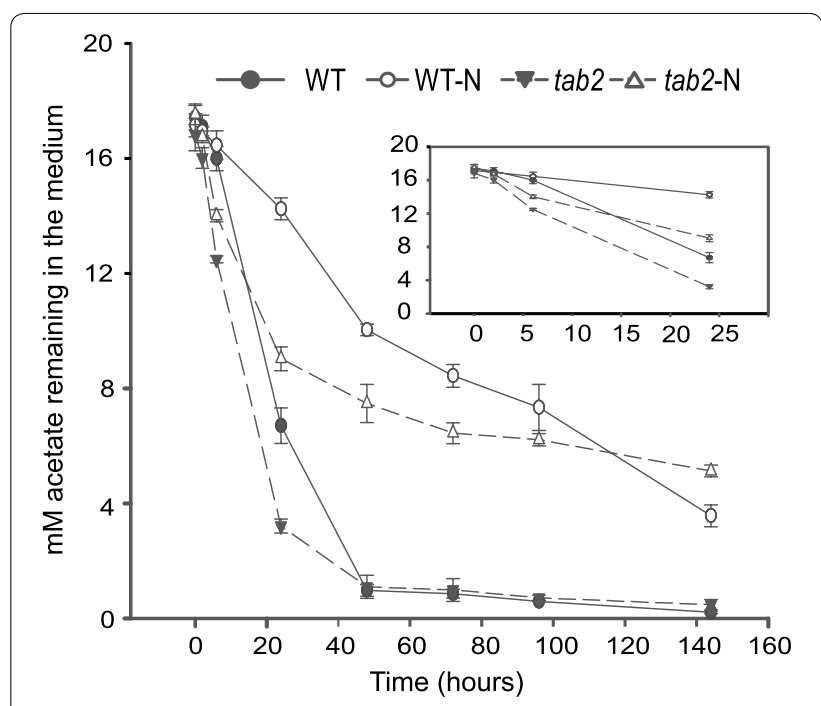

Fig. 9 Acetate consumption in WT and tab2 cells grown in TAP medium under $\mathrm{N}$ replete or $\mathrm{N}$-depleted $(-\mathrm{N})$ conditions, measured by reduction of acetate concentration in the medium. The starting acetate concentration for both conditions was $17 \mathrm{mM}$. Values are averages of triplicate biological samples. Error bars indicate SE

mutation; however, it is unlikely that suppressor mutation promoted the growth only in liquid medium and not in plates. Furthermore, we have been not able to detect any suppressor colonies after the mutant cells growing in liquid HS medium were spread in HS agar plate and allowed to grow for two weeks, because of that we have been working only with HS liquid seed culture to conduct our experiments.

\section{Partitioning of carbon into TAG and starch following $\mathbf{N}$ deprivation is altered in the tab2 mutant}

TAG levels were found to increase in the WT only after $48 \mathrm{~h}$ of $\mathrm{N}$ deprivation (Fig. 8a). In contrast, the tab2 mutant produced $40 \%$ less TAG compared to the WT under these conditions by $48 \mathrm{~h}$, and at 6 days possessed only $17 \%$ of the TAG that the WT accumulated (Fig. 8a). Other mutant strains that were defective in PsaB and PsaA also accumulated low amounts of TAG during $\mathrm{N}$ deprivation (Fig. 8a). This suggests that changes in lipid profiles in the tab2 mutant belong at least partially to a generic cellular response to defects in PSI. Under N deprivation, WT cells demonstrated a major change in the fatty acid profile of the purified TAG compared to cells grown in $\mathrm{N}$ replete conditions. In particular, there was a progressive decrease in omega-3 PUFAs (18:3, 16:3, 16:4) and a corresponding increase in 16:0, 18:1, and 18:2 [36] (Fig. 8b). However, after the initial increase as in wild type, the 18:1 and 18:2 levels in tab2 cells started to decrease after 2 days of $\mathrm{N}$ deprivation, leading eventually (at 6 days) to a threefold decrease compared day 2 . 
It is worthwhile noting that the highest increase for any FA in the mutant was for palmitic acid (fourfold increase) after 6 days of $\mathrm{N}$ deprivation (Fig. 8c). The dramatic decrease of acyl-ACP desaturase (A8IQB8), delta-9ACP desaturase (A8IUT7), and palmitoyl-monogalactosyldiacylglycerol $\Delta 7$-desaturase (FAD5, A8JEN2) levels (Additional file 8: Figure S7) may explain this increase in 16:0. Likewise, the abundance of transcripts encoding enzymes in fatty acid and lipid metabolism (Additional file 9: Figure S8), as well as their protein levels, were either unchanged or decreased in $t a b 2$ versus WT during the $\mathrm{N}$ deprivation time course (Additional file 8: Figure S7). The expression profiles of the diacylglycerol acyltransferases (DGATs) and diacylglycerol acyltransferase type-two enzymes (DGTTs) responsible for the final step of TAG biosynthesis suggested that they were highly down-regulated (in general) in $t a b 2$ versus WT during the course of the $\mathrm{N}$ deprivation experiment (Additional file 9: Figure S8). However, the transcript levels for specific isoforms, DGAT1, DGTT2, and DGTT5, increased initially after the onset of $\mathrm{N}$ starvation (Additional file 9: Figure S8). The early increase of DGAT1 and DGTT2 expression agrees with a previous study of the response of Chlamydomonas to nitrogen deprivation [36], whereas DGTT5 expression has not been detected under either $\mathrm{N}$ or iron starvation [36,37]. In this study, the abundance of DGTT5 transcripts increased early and peaked by $0.5 \mathrm{~h}$ at about twofold higher levels in the mutant versus the WT, after which it decreased (Additional file 9: Figure S8). In addition, the levels of enoyl-CoA hydratase (A8JBL6), involved in the second step of $\beta$-oxidation of fatty acids, decreased twofold in the mutant compared to the WT after 2 days of $\mathrm{N}$ deprivation (Additional file 8: Figure S7). The reduction of $\beta$-oxidation was demonstrated to accompany an increase in neutral lipid levels in Thalassiosira pseudonana [38]. Thus, the changes in TAG composition observed in the mutant compared to the WT appear to be the result of significant changes in the expression and activity of a number of enzymes related to both TAG biosynthesis and FA utilization, including the activity of specific DGATs and DGTTs. This points to a potential critical role for these enzymes, while perhaps not in regulating overall flux into or final levels of TAG, in determining the FA composition of the TAG that accumulates, and thereby at least partially modulating reorganization of membranes as the cell transitions from a growth to a quiescent state $[39,40]$.

In contrast to the low accumulation of TAG, starch levels were significantly higher in $t a b 2$ than in the WT during the time course of $\mathrm{N}$ deprivation (Fig. 7a). The expression levels of many genes encoding different classes of enzymes involved in starch biosynthesis generally increased under $\mathrm{N}$ deprivation in tab2 compared to the WT (Additional file 9: Figure S8). In particular, the transcript levels for certain isoforms of these enzymes, such as glucose-6-phosphate isomerase 1 (PGI1), starch branching enzyme isoforms 1 and 2 (SBE1 and SBE2) and soluble starch synthase isoform 3 (SSS3), increased rapidly in the mutant upon $\mathrm{N}$ depletion, following a pattern similar to that seen for DGAT and DGGTs, and peaked between 0.5 and $2 \mathrm{~h}$ before decreasing (Additional file 9: Figure S8). However, other isoforms of some of these enzymes, such as SBE3 and SSS2, were expressed at higher levels in the WT, and others, such as SSS1, SSS4, and SSS5 remained elevated in expression for a longer time in the mutant. Thus, it was difficult to determine how any given enzyme isoform contributed to the pattern of starch accumulation. In any case, it was clear from the proteomics data (Additional file 10: Figure S9) that by 2 days post-depletion, the mutant had returned to a state of significantly reduced expression for almost all enzymes involved in starch biosynthesis and elevated accumulation of proteins involved in starch degradation, relative to the wild type, in apparent preparation for the subsequent decrease in starch levels that was observed shortly thereafter (Fig. 7a). This enhancement of starch production in the tab2 mutant versus TAG production under $\mathrm{N}$-depleted conditions can be explained by the data presented above regarding ATP, NADPH, and photosystem levels. Because the tab2 mutant cells are unable to maintain an equilibrated energy balance with adequate ATP and NADPH production levels, the carbon that they fix cannot be efficiently converted to TAG, which is a more energy and reducing potential demanding storage molecule than starch. Determining how (and if) post-translational regulation plays a role in regulating starch production in the tab2 mutant versus the WT was beyond the scope of this project and will be the subject of future research.

\section{Omics analysis validates the effect of the tab2 mutation on carbon partitioning during $\mathbf{N}$ deprivation}

If the partitioning of carbon into TAG and starch was altered in the tab2 mutant, then it was likely a result of reprogramming of the central carbon metabolic network. To test this hypothesis, all proteins and metabolites within central metabolism were evaluated for their abundance levels across in both wild-type and mutant cells over a developmental time courses.

\section{The glyoxylate cycle is down-regulated and the TCA cycle up-regulated in the tab2 mutant}

A decrease in the protein abundance of the isocitrate lyase (ICL1) and malate synthase (MS1) isoforms involved in the glyoxylate cycle was observed after 2 days following $\mathrm{N}$ depletion (Additional file 11: Figure S10B) in 
the mutant relative to wild type. This decrease was coincident with a high increase in TCA enzymes after 2 days of $\mathrm{N}$ deprivation. Notably, the levels of the mitochondrial citrate synthase (CIS1) and the four succinate dehydrogenases (SDH1, SDH2, SDH3, and SDH4) that catalyze the oxidation of succinate to fumarate increased up to threefold (Additional file 11: Figure S10B). These results suggest significant enhancement of TCA cycle activity in the mutant during $\mathrm{N}$ deprivation, which is also in line with the higher respiration rate observed in the mutant during the first $48 \mathrm{~h}$ compared to the WT (Fig. 3e).

\section{Glycolysis, gluconeogenesis, and amino acid metabolism are altered in the tab2 mutant}

The TCA cycle is an amphibolic pathway that functions in central metabolism of plants not only to feed metabolic intermediates to the respiratory system for energy production, but also to produce intermediates that leave the cycle to be converted into sugars and amino acids, among a host of other compounds. The protein levels of two enzymes specific for glycolysis, phosphofructokinase 1 and 2, PFK1 (A8HX70) and PFK2 (A8IYM0), increased (Additional file 10: Figure S9B), while the amounts of phosphoenolpyruvate carboxykinase (PCK1A, A8J0N7) and fructose 1,6-bisphosphatase (FBP1, A8IKQ0), required for gluconeogenesis, were greatly decreased in the mutant compared to WT after 2 days of $\mathrm{N}$ deprivation (Additional file 10: Figure S9A). However, the relative expression levels for the two PCK1A isoforms and FBP1 were higher in $t a b 2$ than the WT by $2 \mathrm{~h}$ following $\mathrm{N}$ deprivation (Additional file 9: Figure S8). Moreover, the increase in glycolytic state in $t a b 2$ relative to the WT after 2 days of $\mathrm{N}$ deprivation was also supported by the up-regulation of two alpha-amylases, AMYA1 (A8IYY5) and AMYA2 (A8J4D3), and an increase in glucose levels as well as the sugar phosphate, Glc6P (Additional file 12: Figure S11). A previous report demonstrated that Chlamydomonas cells respond rapidly to $\mathrm{N}$ deprivation by immediately turning on a gluconeogenic state and then by about $6 \mathrm{~h}$ repatterning metabolism to shift to a largely glycolytic state [41]. These results suggest that such a response was enhanced in the TCA cycle of tab2 cells.

In addition, amino acid synthesis was reorganized in the tab2 mutant compared to the WT. A strong decrease of the levels of the enzymes involved in the synthesis of aromatic amino acids, alanine, valine, isoleucine and leucine was observed. In contrast, an increase of the cytosolic glutamine synthetase (GLNA1) and the chloroplastic form (GLNA2), as well as glutamate dehydrogenase (GHD2) and aspartate aminotransferase (AST1) was observed. This was accompanied by a general stimulation of arginine synthesis, as evidenced through the up-regulation of argininosuccinate synthase (AGS1), argininosuccinate lyase (ARG7), and ornithine carbamoyltransferase (OTC1) (Additional file 13: Figure S12). These results led us to carefully examine the levels of each of the amino acids across the time courses. As expected, the amounts of glutamine and arginine showed greater accumulation within the last 3 days of the $\mathrm{N}$ deprivation time course in $t a b 2$ compared to the WT (Additional file 14: Figure S13). The increase in accumulation of these amino acids is likely the result of the increase in flux through the TCA cycle to produce substrates for amino acid biosynthesis.

All of these results suggest that a shift towards the synthesis of specific amino acids as opposed to general amino acid degradation occurs in the tab2 mutant during $\mathrm{N}$ deprivation. Glutamine and arginine play a critical role in $\mathrm{C} / \mathrm{N}$ partitioning and $\mathrm{N}$ assimilation in plant cells, and considering the $\mathrm{N}$-depleted conditions experienced by the cells in the experiment, it appears that the mutant cells actively maintain high levels of these metabolites (by rapid turnover) compared to the WT cells, thus enabling a rapid response to changing $\mathrm{N}$ levels that the cells may experience. Interestingly, it was also noticed that the amounts of several enzymes involved in autophagy, such as proteases (cysteine protease CEP, serine proteases, Deg-P type protease) are significantly increased in $t a b 2$ (Additional file 15: Figure S14B) and could also contribute to the high level of amino acids detected above.

\section{Fatty acid catabolism is increased in the tab2 mutant during $\mathbf{N}$ deprivation}

The increase in glycerol amounts (Additional file 12: Figure S11) and the level of dihydroxyacetone kinase (DAK1, A8JB14) after 2 days of $\mathrm{N}$ deprivation followed the up-regulation of many enzymes involved in fatty acid catabolism (Additional file 8: Figure S7) suggests that an increase in fatty acid degradation may be used by $t a b 2$ cells to feed acetyl-CoA into the TCA cycle to support the reprograming of metabolic flux (Fig. 10).

\section{The knockdown of TAB2 levels leads to an increase in specific enzymes required for elimination of reactive oxygen species}

Any process that disrupts the maintenance of proper ATP/NADPH ratios can also lead to the formation of reactive oxygen species (ROS) [42]. Protein levels of many enzymes involved in the protection against ROS in mitochondria (e.g., MSD1, GPX3, and CCPR1) and in the chloroplast (FSD1, APX1) were found to be strongly up-regulated only in tab2 (not in WT) during $\mathrm{N}$ deprivation (Additional file 15: Figure S14A), although their mRNA transcript levels did not show a significant change compared to the WT (Additional file 9: Figure S8). Several other oxidative stress-related enzymes were also 


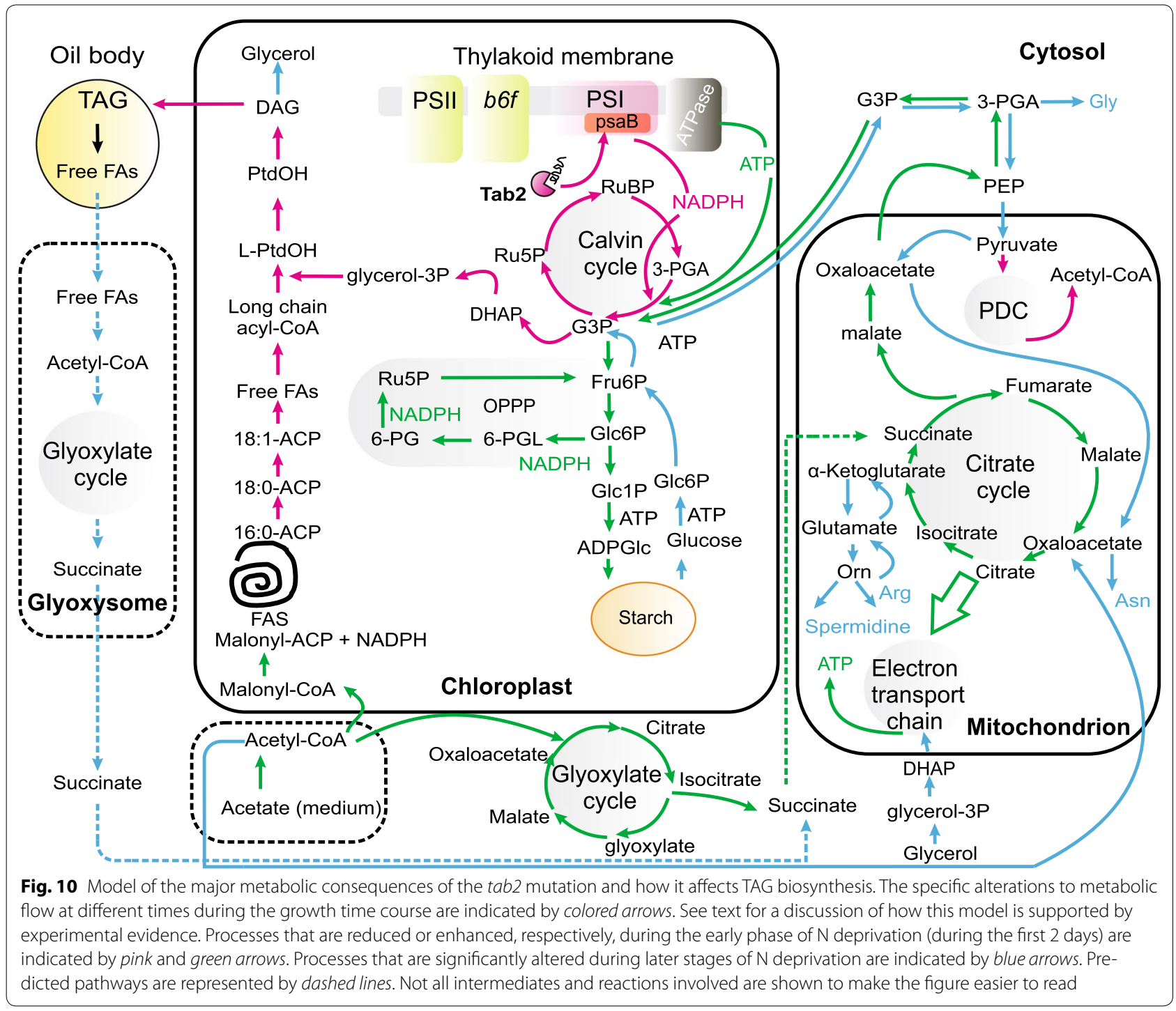

up-regulated in tab2, such as GST1 (A8JBB4) and GSH1 (A8IA77), and could function in protecting against singlet oxygen stress [43] by being involved in the detoxification of ROS produced as a result of decreased PSI levels [44]. In contrast, MDAR (A8JDG4), which is required to generate ascorbate using NADPH [45], was up-regulated instead, but only in the WT, which as described above maintained higher NADPH levels than the mutant. The divergence of transcript and protein expression in these cases implicates post-transcriptional regulation of oxidative stress protection. Herein, the loss of the ability to accumulate TAG in $t a b 2$ was correlated to the up-regulation of enzymes involved in ROS protection, supporting the hypothesis that TAG synthesis is not only a consumer process of photosynthetic resources for carbon storage [25], but may also be important for the efficient oxidation of reduced NADPH to prevent over reduction of electron transfer systems and ROS production.

\section{Discussion}

Altered photosynthetic activity in the presence of acetate and $\mathrm{N}$ enhances TAG and starch accumulation in the tab2 mutant

The tab2 mutation leads to the accumulation of neutral lipids and starch in cells growing mixotrophically on acetate medium supplied with sufficient $\mathrm{N}$ amounts, particularly within the first 2 days of the growth time course (Figs. 6, 7a). This was an unexpected result. Previous studies with other $C$. reinhardtii (particularly WT) strains observed a reduction in photosynthetic efficiency, growth, and carbon fixation in N-depleted cells [16]. One explanation for the higher accumulation of these storage 
compounds in the tab2 mutant compared to WT may be increased activity of acetyl-CoA synthetase and the glyoxylate pathway. Acetate consumption was higher in the mutant than the WT under N replete conditions (Fig. 8), thus confirming this hypothesis. However, no significant accumulation of starch and neutral lipids was observed when the cells were grown without acetate or under dark conditions. This led to the hypothesis that altered photosynthetic efficiency, such as was caused by the knockdown of the TAB2 protein levels in this study, may be a condition required to promote energy storage compound accumulation in Chlamydomonas cells, independent of removal of $\mathrm{N}$ or other nutrients from the medium, but that sufficient carbon must nevertheless be available. Thus, it is possible that specific alterations of photosynthetic efficiency may be identified that lead to enhanced lipid accumulation in algal cells without the requirement for changes in media conditions that lead to cessation of growth.

In response to $\mathrm{N}$ deprivation stress, the accumulation of TAG in the WT lagged behind starch production [25]. That may be due to the temporal separation between the responses of transcript abundances for these two pathways that was observed in the WT strain [10]. However, this temporal separation was affected by the $t a b 2$ mutation under $\mathrm{N}$ replete conditions, where neutral lipids accumulated within the first 2 days, at the same time as the accumulation of starch. Lipid levels then decreased while starch increased slightly until day 6 (Figs. 6, 7a). The observation that neutral lipids accumulate at a faster rate than starch in the mutant during the first 2 days under $\mathrm{N}$ replete conditions suggests that the accumulation of TAG in the presence of acetate is more likely a direct response to disrupted photosynthetic efficiency than to the prior accumulation of starch, which is consistent with the view that in Chlamydomonas starch and TAG accumulation have different purposes [25]. These findings suggest that TAG accumulates not only as a carbon sink for growth arrested cells but also as a means to protect the photosynthetic machinery under adverse conditions, as suggested by [28], or it could serve as a storage pool that can be readily remobilized to restore thylakoid membranes and photosynthetic activity [8].

\section{Metabolic shift towards amino acids accumulation in the absence of TAG biosynthesis during $\mathbf{N}$ deprivation}

The transcript mRNA level of ICL and MAS1 were upregulated after only $2 \mathrm{~h}$ following $\mathrm{N}$ deprivation and remind higher up to $24 \mathrm{~h}$ in the mutant versus WT (Additional file 9: Figure S8). This increase was followed by the accumulation of malate (Additional file 12: Figure S11) and a higher respiration in the mutant (Fig. 3e) particularly during the first $6 \mathrm{~h}$ following $\mathrm{N}$ deprivation, indicating that the excess of acetyl-CoA was fueled most likely into glyoxylate cycle after the onset of $\mathrm{N}$ deprivation and then oxidized to produce NADH and FADH2 for the respiratory chain that leads to high production of ATP in the mutant (Fig. 10). In line, several genes involved for gluconeogenesis increased during the first hours of $\mathrm{N}$ deprivation (Additional file 9: Figure S8) coordinately with the increase level of G3P (Additional file 12: Figure S11) suggesting that the abundant ATP is exported out of the mitochondria and participates to reverse phosphoglycerate kinase activity in the cytosol and leads to the formation of G3P. Since we observed a high accumulation of starch in the mutant as compared to the WT followed by a dramatic decrease of G3P level (Additional file 12: Figure S11), it is possible that a major part of the G3P imported to the chloroplast can be used for the gluconeogenesis and the high accumulation of carbohydrates than the accumulation of fatty acids (Fig. 10), thus supporting our interpretation that TAG synthesis serves as a cul-de-sac for the excess of acetyl-CoA produced from acetate in the presence of an adequate amount of reductant.

After 2 days of $\mathrm{N}$ deprivation and with a decrease of acetate assimilation rate, a strong decrease of respiration and in the amounts of enzymes involved in the glyoxylate cycle and gluconeogenesis was observed in the tab2. This decrease was correlated a high increase of the amount of TCA enzymes (Additional file 11: Figure S10B). One possibility is raised by this observation that the acetylCoA was fueled preferentially to TCA cycle without any bypass to glyoxylate cycle. The up-regulation of TCA cycle enzymes was coupled with the up-regulation of glycolysis enzymes, an accumulation of glycerol (resulted probably from an active fatty acids turnover) and an elevated amount of several amino acids in the tab2 mutant after 4 days of $\mathrm{N}$ deprivation. The increase of glutamate synthesis was concomitant with up-regulation of ARG9 an acetyl-ornithine aminotransferase involved in the recycling of glutamate from ornithine (Additional file 13: Figure S12). Since the amount of alpha-ketoglutarate was remained constant in tab2 during $\mathrm{N}$ deprivation (Additional file 12: Figure S11). This observation suggests that once the glutamate is produced, it is distributed to other amino acids that in turn participate in the regeneration of alpha-ketoglutarate that can then be used to re-fuel the TCA cycle with no net energy expense [17]. Additionally, the synthesis of amino acids can serve as important precursors for metabolite biosynthesis, such as polyamines, nucleotides, and enzyme cofactors. Pursuant to this observation, the amount of the spermidine was noted to have accumulated slightly more in $t a b 2$ than the WT. Elevated amino acids have been also observed in Chlamydomonas after knockout of isocitrate lyase 
[46]. This suggests that the accumulation of amino acids maintains the mitochondrial $\mathrm{pH}$ and reduces the acidic stress caused by the accumulation of organic acids. These results suggest that the knockdown of TAB2 leads to a harmful metabolic shift towards amino acids during $\mathrm{N}$ deprivation in the presence of acetate, which can be avoided if the cells maintain the correct energy balance required for the accumulation of TAG.

\section{A proposed model for regulation of metabolism in the tab2 mutant}

One of the major objectives of this study was to better understand why algal cells produce TAG under nutrientstressed conditions. In response to $\mathrm{N}$ starvation stress, acetate (if provided in the growth medium) is assimilated to form acetyl-CoA and in WT cells is available to feed preferentially to the glyoxylate and citrate cycles during the first hours following the nutrient stress to yield succinate, malate, and oxaloacetate, which in turn can be converted into phosphoenolpyruvate to be used by gluconeogenesis to support cellular growth or other energy demanding metabolic processes, which are also supported by a fully functional photosynthetic apparatus. However, because nitrogen deprivation has been sensed and metabolism repatterning begun [41], the cells initiate a process whereby they switch from that gluconeogenic state to first a glycolytic state and eventually to accumulation of TAG instead of enhanced cellular growth. The quick response at the onset of $\mathrm{N}$ deprivation is an energy demanding process that consumes ATP and leads to a dramatic disruption of the ATP/NADPH ratio, as was described in this report. The WT cells, with fully functional PSI, are able to support the cellular growth for a time, during the transition to the strongly glycolytic state. But eventually they cease growth and turn on TAG production, leading eventually to accumulation of significant TAG levels.

In the tab2 mutant cells, which have not only significantly reduced levels of PSI compared to WT but also dramatically altered proteomes as well, the metabolic response to $\mathrm{N}$ deprivation is quite different. During the early phase of $\mathrm{N}$ deprivation (during the first 2 days), $\mathrm{NADPH}$ production is reduced compared to the WT, as highlighted by the large increase in the ATP:NADPH ratio described above. This leads to reduced Calvin cycle activity, reduced fatty acid biosynthesis and lower TAG production (the pink arrows in Fig. 10 indicate metabolic processes that are reduced in the $t a b 2$ mutant during this early stage). During the first 2 days, acetate imported from the medium could theoretically be used to generate malonyl-CoA and thus support FA biosynthesis, but because of the reduced NADPH availability (due to lower PSI levels), FA and TAG syntheses are not well supported.
Instead, the excess acetyl-CoA (formed from the acetate imported from the medium) feeds into the glyoxylate and citrate cycles and leads to elevated production of ATP and production of glyceraldehyde-3-phosphate (green arrows in Fig. 10), as was seen for the WT, to be used to support elevated gluconeogenesis. However, instead of being used to support cell growth, the oxidative pentose phosphate pathway (OPPP) is activated to produce what $\mathrm{NADPH}$ is required for maintenance of cellular function, and gluconeogenesis serves the function of producing starch, a lower reductant-demanding storage molecule than TAG.

During the later stages of $\mathrm{N}$ deprivation, when acetate has been depleted from the medium, protein synthesis/ regeneration cannot be supported due also to reduced $\mathrm{N}$ availability. Amino acid biosynthesis is reorganized in the tab2 mutant under those conditions, with aromatic and branched chain amino acid biosynthesis being shut down in favor of maintenance of pools of amino acids that are closely connected to the citrate cycle and that could quickly respond to enable assimilation of $\mathrm{N}$, should a new source of that critical nutrient become available in the environment surrounding the cell. That is similar to what occurs in WT cells [41]. However, in the tab2 mutant succinate connects the cytosolic and peroxisomal glyoxylate cycles to the citrate cycle, supporting this potential assimilation priming. In the WT cells, TAG is produced at this stage of $\mathrm{N}$ starvation, to serve both as a storage molecule and potentially as a mechanism to protect the cell from oxidative damage associated with the $\mathrm{N}$ starvation state, leading eventually to entrance into the quiescent state outlined above. The $t a b 2$ cells, on the other hand, suffer from the inability both to produce TAG and to protect themselves from oxidative damage, due to reduced NADPH availability.

The increased acetate utilization by the tab2 cells compared to the WT does not increase TAG accumulation, supporting the idea that TAG biosynthesis in Chlamydomonas may play more of a role in regulating the energy balance in the cell than in serving as a carbon sink. Likewise, the GND and GLD enzymes involved in NADPH production by the oxidative pentose phosphate pathway are highly up-regulated in the mutant (Additional file 15: Figure S14C) indicating that NADPH produced through the oxidation of the G6P may not contribute to the TAG accumulation process in Chlamydomonas. These findings support the conclusion that TAG synthesis in Chlamydomonas either depends on active photosynthesis or plays a role that is greater than just generic bulk carbon storage. It is thus likely that the knockdown of TAB2 causes a severe photo-oxidative stress in the mutant followed by the production of ROS. Although we did not measure augmentation in vivo, we 
found that the enzymes involved against ROS are highly up-regulated in the mutant versus WT, which is not surprising. This result suggests that the TAG biosynthesis could involve protecting the photosynthetic machinery from the photodamage through the regeneration of $\mathrm{NADP}+$ which can accept electrons and thus reduce the production of ROS.

Thus, efforts to increase lipid accumulation in algae such as Chlamydomonas need to consider carefully how the energy balance of the cell is involved in or affected by such efforts and that numerous layers of metabolic and genetic regulatory control are likely interfered with such efforts to control oil biosynthesis.

\section{Conclusions}

In this study, we conducted a detailed physiological and omics-based analysis of an insertional mutant of Chlamydomonas with reduced TAB2 function to determine what role this protein may play in regulating the cellular response to $\mathrm{N}$ deprivation. TAB2 is a photosystem I (PSI) translation initiation factor, whose transcript and protein levels increase significantly after only $30 \mathrm{~min}$ of $\mathrm{N}$ deprivation. The tab2 mutant displayed reduced TAG content and altered fatty acid profiles, along with increased starch and acetate assimilation during the first $6 \mathrm{~h}$ of $\mathrm{N}$ deprivation, followed by a metabolites shift towards amino acid synthesis, revealing the central role of functional PSI in controlling lipid/starch partitioning. A time course analysis of the ATP/NADPH ratio in the mutant vs. wild type suggested that TAG biosynthesis may be associated with maintaining the redox state of the cell during $\mathrm{N}$ deprivation. The loss of ability to accumulate TAG in the tab2 mutant co-occurred with an up-regulation of photo-protective mechanism and autophagy, suggesting that the synthesis of TAG in the wild type occurs not only as a temporal energy sink, but also as a protective mechanism. Such knowledge will enable synthetic biology approaches to alter the response to the $\mathrm{N}$ depletion stress, leading to rewiring of the regulatory networks so that lipid accumulation could be turned on in the absence of $\mathrm{N}$ deprivation, allowing for the development of algal production strains with highly enhanced lipid accumulation profiles.

\section{Additional files}

Additional file 1: Table S1. The list of primers used for the quantitative real-time PCR results for the WT and tab2.

Additional file 2: Figure S1. Key for visualization of protein expression levels via heat maps of chlorophyll and carotenoids biosynthesis. In heat maps protein expression levels of all conditions (WT at time 0, WT after 48 $\mathrm{h}$ of $\mathrm{N}$ deprivation, $\mathrm{tab} 2$ at time 0 and tab2 after $48 \mathrm{~h}$ of $\mathrm{N}$ deprivation) are compared. The shown mean ratios are log2.
Additional file 3: Figure S2. Correlation diagram of TAG content/ Starch and Cell size area during $N$ deprivation in the WT (A) and in tab2 (B), Correlation of starch content with cell area size is represented with solid triangles and dash line. Correlation of TAG content with cell area size is represented with solid circles.

Additional file 4: Figure S3. Key for visualization of protein expression levels via heat maps of photosystem complexes. In the heat maps, protein expression levels of all conditions (WT at time $0, W T$ after $48 \mathrm{~h}$ of $\mathrm{N}$ deprivation, tab2 at time 0 and tab2 after $48 \mathrm{~h}$ of $\mathrm{N}$ deprivation) are compared. The shown mean ratios are log2.

Additional file 5: Figure S4. Key for visualization of protein expression levels via heat maps of mitochondrial electron transport mechanisms. In the heat maps, protein expression levels of all conditions (WT at time $0, \mathrm{WT}$ after $48 \mathrm{~h}$ of $\mathrm{N}$ deprivation, tab2 at time 0 and tab2 after $48 \mathrm{~h}$ of $\mathrm{N}$ deprivation) are compared. The shown mean ratios are log2.

Additional file 6: Figure S5. The 77K Steady State Fluorescence Emission Spectra of C. reinhardtii WT Cells grown in TAP media during N deprivation. The amplitude of the PSII-associated signal (around $685 \mathrm{~nm}$ ) and the PSI-associated signal (around $715 \mathrm{~nm}$ ).

Additional file 7: Figure S6. Detailed Lipid analysis of the wild-type and tab2 in N+ conditions. (A) Changes in TAG content in the wild-type and tab2. (B) Mol (\%) of esterified fatty acids in TAG isolated from $\mathrm{N}+$ condition cells in the Wild-type (C) and in tab2 (D). Time points presented are 0,2 , 4,6 and 8 days. Values are representative of triplicate biological samples. Error bars indicate SE means.

Additional file 8: Figure S7. Visualization of protein expression levels for fatty acid biosynthesis. Heat maps compare protein expression levels relative to wild type time 0 (WT Oh), including WT after $48 \mathrm{~h}$ of $\mathrm{N}$ deprivation, tab2 at time 0 and tab2 after $48 \mathrm{~h}$ of $\mathrm{N}$ deprivation. The ratios are displayed in $\log 2$ scale.

Additional file 9: Figure S8. Quantitative real-time PCR Results for WT and tab2. The transcript level was represented by white bars for the WT and black bars for the mutant. Time points presented are $0.5,2,6,24,72 \mathrm{~h}$.

Additional file 10: Figure S9. Key for visualization of protein expression levels via heat maps of (A) gluconeogenesis and starch biosynthesis and (B) glycolysis and starch catabolism. In the heat maps, protein expression levels of all conditions (WT at time $0, \mathrm{WT}$ after $48 \mathrm{~h}$ of $\mathrm{N}$ deprivation, tab2 at time 0 and tab2 after $48 \mathrm{~h}$ of $\mathrm{N}$ deprivation) are compared. The shown mean ratios are $\log 2$.

Additional file 11: Figure S10. Key for visualization of protein expression levels via heat maps of (A) acetate uptake and (B) central metabolism. In the heat maps, protein expression levels of all conditions (WT at time $0, \mathrm{WT}$ after $48 \mathrm{~h}$ of $\mathrm{N}$ deprivation, tab2 at time 0 and tab2 after $48 \mathrm{~h}$ of $\mathrm{N}$ deprivation) are compared. The shown mean ratios are log2.

Additional file 12: Figure S11. Metabolic profiles of the WT and the tab2. Time points presented are $0,0.5,2,6,24,48,72,96,120,144 \mathrm{~h}$. Data are normalized to the means' standard deviations. Circles correspond to the WT profile. Squares corresponded to the tab2 profile.

Additional file 13: Figure $\mathbf{S 1 2}$. Key for visualization of protein expression levels via heat maps of amino acids and polyamines. In the heat maps, protein expression levels of all conditions (WT at time 0 , WT after 48 $\mathrm{h}$ of $\mathrm{N}$ deprivation, tab2 at time 0 and tab2 after $48 \mathrm{~h}$ of $\mathrm{N}$ deprivation) are compared. The shown mean ratios are log2.

Additional file 14: Figure S13. Time-course amino acids profile during $\mathrm{N}$ deprivation in the $\mathrm{WT}$ and tab2. Time points presented are $0,0.5,2$, $6,24,48,72,96,120,144 \mathrm{~h}$. Data are normalized to the means standard deviation. Squares corresponded to the WT profile. Circles corresponded to the tab2 profile.

Additional file 15: Figure S14. Key for visualization of protein expression levels via heat maps of (A) ROS protection, (B) proteolysis and (C) OPPP. In the heat maps, protein expression levels of all conditions (WT at time 0 , WT after $48 \mathrm{~h}$ of $\mathrm{N}$ deprivation, tab2 at time 0 and tab2 after $48 \mathrm{~h}$ of $\mathrm{N}$ deprivation) are compared. The shown mean ratios are log2. 


\section{Authors' contributions}

DRG, MG, PDB, and HK designed experiments. MG cultured and harvested algae and performed all extractions. MG and PDB generated lipid data. J.JP generated metabolite profiling data. HK supervised photosynthesis analysis. MG, JJP performed the bioinformatic and statistical analysis of omics data. MG wrote the manuscript. DRG supervised all analyses and revised the manuscript. All authors read and approved the final manuscript.

\section{Author details}

${ }^{1}$ Institute of Biological Chemistry, Washington State University, Pullman, WA 99164, USA. ${ }^{2}$ Present Address: Laboratory of Plant Molecular Physiology, Center of Biotechnology of Borj Cedria, P.O. Box 901, 2050 Hammam-Lif, Tunisia. ${ }^{3}$ Present Address: Department of Chemistry and Biochemistry, The University of Southern Mississippi, Hattiesburg, MS 39406, USA.

\section{Acknowledgements}

We wish to thank Dr. Sandrine Buljaldon from IBPC (France) for providing us with the photosynthesis I mutants of Chlamydomonas. We also thank Dr. Steven R. Danielson and Dr. Jennifer Sutton from Thermo for running protein samples on the Thermo Fusion Tribrid mass spectrometer system. We also wish to thank Dr. David Kramer for valuable discussions about the photosynthetic fluorescence measurements.

\section{Competing interests}

The authors declare that they have no competing interests.

\section{Availability of data and materials}

See Additional files 1, 2, 3, 4, 5, 6, 7, 8, 9, 10, 11, 12, 13, 14, 15 .

\section{Funding}

This work was supported as part of the Center for Advanced Biofuels Systems (CABS), an Energy Frontier Research Center funded by the U.S. Department of Energy, Office of Science, Office of Basic Energy Sciences under Award Number DE-SC0001295.

\section{Publisher's Note}

Springer Nature remains neutral with regard to jurisdictional claims in published maps and institutional affiliations.

\section{Received: 20 July 2016 Accepted: 5 April 2017}

Published online: 13 April 2017

\section{References}

1. Merchant S, Kropat J, Liu B, Shaw J, Warakanont J. TAG, You're it! Chlamydomonas as a reference organism for understanding algal triacylglycerol accumulation. Curr Opin Biotechnol. 2012;23:352-63.

2. Georgianna DR, Mayfield SP. Exploiting diversity and synthetic biology for the production of algal biofuels. Nature. 2012;488(7411):329-35.

3. Bates PD, Stymne S, Ohlrogge J. Biochemical pathways in seed oil synthesis. Curr Opin Plant Biol. 2013;16(3):358-64.

4. Wilhelm C, Jakob T. From photons to biomass and biofuels: evaluation of different strategies for the improvement of algal biotechnology based on comparative energy balances. Appl Microbiol Biotechnol. 2011;92(5):909-19.

5. Rodolfi L, Chini Zittelli G, Bassi N, Padovani G, Biondi N, Bonini G, Tredici MR. Microalgae for oil: strain selection, induction of lipid synthesis and outdoor mass cultivation in a low-cost photobioreactor. Biotechnol Bioeng. 2009;102(1):100-12.

6. Wase N, Black PN, Stanley BA, DiRusso CC. Integrated quantitative analysis of nitrogen stress response in Chlamydomonas reinhardtii using metabolite and protein profiling. J Proteome Res. 2014;13(3):1373-96.

7. Schmollinger S, Mühlhaus T, Boyle NR, Blaby IK, Casero D, Mettler T, Moseley JL, Kropat J, Sommer F, Strenkert D, et al. Nitrogen-sparing mechanisms in Chlamydomonas affect the transcriptome, the proteome, and photosynthetic metabolism. Plant Cell. 2014;26(4):1410-35.
8. Juergens MT, Deshpande RR, Lucker BF, Park J-J, Wang H, Gargouri M, Holguin FO, Disbrow B, Schaub T, Skepper JN, et al. The regulation of photosynthetic structure and function during nitrogen deprivation in Chlamydomonas reinhardtii. Plant Physiol. 2015;167(2):558-73.

9. Lee DY, Park J-J, Barupal DK, Fiehn O. System response of metabolic networks in Chlamydomonas reinhardtii to total available ammonium. Mol Cell Proteomics. 2012;11(10):973-88.

10. Blaby IK, Glaesener AG, Mettler T, Fitz-Gibbon ST, Gallaher SD, Liu B, Boyle NR, Kropat J, Stitt M, Johnson S, et al. Systems-level analysis of nitrogen starvation-induced modifications of carbon metabolism in a Chlamydomonas reinhardtii starchless mutant. Plant Cell. 2013;25(11):4305-23.

11. Radakovits R, Jinkerson RE, Darzins A, Posewitz MC. Genetic engineering of algae for enhanced biofuel production. Eukaryot Cell. 2010;9(4):486-501.

12. Fan J, Yan C, Andre C, Shanklin J, Schwender J, Xu C. Oil accumulation is controlled by carbon precursor supply for fatty acid synthesis in Chlamydomonas reinhardtii. Plant Cell Physiol. 2012;53(8):1380-90.

13. Msanne J, Xu D, Konda AR, Casas-Mollano JA, Awada T, Cahoon EB, Cerutti $\mathrm{H}$. Metabolic and gene expression changes triggered by nitrogen deprivation in the photoautotrophically grown microalgae Chlamydomonas reinhardtii and Coccomyxa sp. C-169. Phytochemistry. 2012;75:50-9.

14. Berges JA, Charlebois DO, Mauzerall DC, Falkowski PG. Differential effects of nitrogen limitation on photosynthetic efficiency of photosystems I and II in microalgae. Plant Physiol. 1996;110(2):689-96.

15. Simionato D, Block MA, La Rocca N, Jouhet J, Marechal E, Finazzi G, Morosinotto T. The response of Nannochloropsis gaditana to nitrogen starvation includes de novo biosynthesis of triacylglycerols, a decrease of chloroplast galactolipids, and reorganization of the photosynthetic apparatus. Eukaryot Cell. 2013;12(5):665-76.

16. Miller R, Wu G, Deshpande RR, Vieler A, Gärtner K, Li X, Moellering ER, Zäuner S, Cornish AJ, Liu B, et al. Changes in transcript abundance in Chlamydomonas reinhardtii following nitrogen deprivation predict diversion of metabolism. Plant Physiol. 2010;154(4):1737-52.

17. Longworth J, Noirel J, Pandhal J, Wright PC, Vaidyanathan S. HILIC- and SCX-based quantitative proteomics of Chlamydomonas reinhardtii during nitrogen starvation induced lipid and carbohydrate accumulation. J Proteome Res. 2012;11(12):5959-71.

18. Li-Beisson $Y$, Shorrosh B, Beisson F, Andersson MX, Arondel V, Bates PD, Baud S, Bird D, DeBono A, Durrett TP, Franke RB, Graham IA, Katayama K, Kelly AA, Larson T, Markham JE, Miquel M, Molina I, Nishida I, Rowland O, Samuels L, Schmid KM, Wada H, Welti R, Xu C, Zallot R. Ohlrogge J Acyllipid metabolism. The Arabidopsis Book. 2013:11:e0161.

19. Gargouri M, Park J-J, Holguin FO, Kim M-J, Wang H, Deshpande RR, Shachar-Hill Y, Hicks LM, Gang DR. Identification of regulatory network hubs that control lipid metabolism in Chlamydomonas reinhardtii. J Exp Bot. 2015:66:4551.

20. Dauvillee D, Stampacchia O, Girard-Bascou J, Rochaix J-D. Tab2 is a novel conserved RNA binding protein required for translation of the chloroplast psaB mRNA. EMBO J. 2003;22(23):6378-88.

21. Harris EH. The Chlamydomonas sourcebook: a comprehensive guide to biology and laboratory use. San Diego: Academic Press; 1989.

22. Sueoka N. Mitotic replication of deoxyribonucleic acid in Chlamydomonas reinhardtii. Proc Natl Acad Sci. 1960;46(1):83-91.

23. Wang H, Alvarez S, Hicks LM. Comprehensive comparison of iTRAQ and label-free LC-based quantitative proteomics approaches using two Chlamydomonas reinhardtii strains of interest for biofuels engineering. J Proteome Res. 2012;11(1):487-501.

24. Li Y, Beisson F, Pollard M, Ohlrogge J. Oil content of Arabidopsis seeds: the influence of seed anatomy, light and plant-to-plant variation. Phytochemistry. 2006:67(9):904-15.

25. Siaut M, Cuine S, Cagnon C, Fessler B, Nguyen M, Carrier P, Beyly A, Beisson F, Triantaphylides C, Li-Beisson Y, et al. Oil accumulation in the model green alga Chlamydomonas reinhardtii: characterization, variability between common laboratory strains and relationship with starch reserves. BMC Biotechnol. 2011;11(1):7.

26. Arnon DI. Copper enzymes in isolated chloroplasts. Polyphenoloxidase in Beta vulgaris. Plant Physiol. 1949;24(1):1-15. 
27. Chow PS, Landhausser SM. A method for routine measurements of total sugar and starch content in woody plant tissues. Tree Physiol. 2004;24(10):1129-36.

28. Li X, Moellering ER, Liu B, Johnny C, Fedewa M, Sears BB, Kuo M-H, Benning C. A galactoglycerolipid lipase is required for triacylglycerol accumulation and survival following nitrogen deprivation in Chlamydomonas reinhardtii. Plant Cell. 2012;24(11):4670-86.

29. van Kooten $\mathrm{O}$, Snel JH. The use of chlorophyll fluorescence nomenclature in plant stress physiology. Photosynth Res. 1990;25(3):147-50.

30. Maxwell K, Johnson GN. Chlorophyll fluorescence-a practical guide. J Exp Bot. 2000;51(345):659-68.

31. Kramer D, Crofts A. Demonstration of a highly-sensitive portable doubleflash kinetic spectrophotometer for measurement of electron transfer reactions in intact plants. Photosynth Res. 1990;23(2):231-40.

32. Kramer D, Sacksteder C. A diffused-optics flash kinetic spectrophotometer (DOFS) for measurements of absorbance changes in intact plants in the steady-state. Photosynth Res. 1998;56(1):103-12.

33. Dean AP, Sigee DC, Estrada B, Pittman JK. Using FTIR spectroscopy for rapid determination of lipid accumulation in response to nitrogen limitation in freshwater microalgae. Biores Technol. 2010;101(12):4499-507.

34. Kramer D, Johnson G, Kiirats O, Edwards G. New fluorescence parameters for the determination of QA redox state and excitation energy fluxes. Photosynth Res. 2004;79(2):209-18.

35. Subramanian S, Barry A, Pieris S, Sayre R. Comparative energetics and kinetics of autotrophic lipid and starch metabolism in chlorophytic microalgae: implications for biomass and biofuel production. Biotechnol Biofuels. 2013;6(1):150.

36. Boyle NR, Page MD, Liu B, Blaby IK, Casero D, Kropat J, Cokus SJ, HongHermesdorf A, Shaw J, Karpowicz SJ, et al. Three acyltransferases and nitrogen-responsive regulator are implicated in nitrogen starvationinduced triacylglycerol accumulation in Chlamydomonas. J Biol Chem. 2012;287(19):15811-25.
37. Urzica El, Vieler A, Hong-Hermesdorf A, Page MD, Casero D, Gallaher SD, Kropat J, Pellegrini M, Benning C, Merchant SS. Remodeling of membrane lipids in iron starved Chlamydomonas. J Biol Chem. 2013;288:30246.

38. Trentacoste EM, Shrestha RP, Smith SR, Glé C, Hartmann AC, Hildebrand M, Gerwick WH. Metabolic engineering of lipid catabolism increases microalgal lipid accumulation without compromising growth. Proc Natl Acad Sci. 2013;110:19748.

39. Tsai C-H, Warakanont J, Takeuchi T, Sears BB, Moellering ER, Benning C. The protein compromised hydrolysis of triacylglycerols 7 (CHT7) acts as a repressor of cellular quiescence in Chlamydomonas. Proc Natl Acad Sci. 2014;111(44):15833-8.

40. Valcourt JR, Lemons JMS, Haley EM, Kojima M, Demuren OO, Coller HA. Staying alive. Metabolic adaptations to quiescence. Cell Cycle. 2012;11(9):1680-96

41. Park J-J, Gargouri M, Wang H, Deshpande R, Skepper J, Holguin FO, Juergens M, Shachar-Hill Y, Hicks LM, Gang DR. The response of Chlamydomonas reinhardtii to nitrogen deprivation: a systems biology analysis. Plant J. 2015;81(4):611-24.

42. Kramer DM, Evans JR. The importance of energy balance in improving photosynthetic productivity. Plant Physiol. 2011;155(1):70-8.

43. Ledford HK, Chin BL, Niyogi KK. Acclimation to singlet oxygen stress in Chlamydomonas reinhardtii. Eukaryot Cell. 2007;6(6):919-30.

44. Ort DR, Baker NR. A photoprotective role for $\mathrm{O}_{2}$ as an alternative electron sink in photosynthesis? Curr Opin Plant Biol. 2002;5(3):193-8.

45. Hossain MA, Nakano Y, Asada K. Monodehydroascorbate reductase in spinach chloroplasts and its participation in regeneration of ascorbate for scavenging hydrogen peroxide. Plant Cell Physiol. 1984;25(3):385-95.

46. Plancke C, Vigeolas H, Höhner R, Roberty S, Emonds-Alt B, Larosa V, Willamme R, Duby F, Onga Dhali D, Thonart P, et al. Lack of isocitrate lyase in Chlamydomonas leads to changes in carbon metabolism and in the response to oxidative stress under mixotrophic growth. Plant J. 2014;77(3):404-17.

\section{Submit your next manuscript to BioMed Central and we will help you at every step:}

- We accept pre-submission inquiries

- Our selector tool helps you to find the most relevant journal

- We provide round the clock customer support

- Convenient online submission

- Thorough peer review

- Inclusion in PubMed and all major indexing services

- Maximum visibility for your research

Submit your manuscript at www.biomedcentral.com/submit
() Biomed Central 